\title{
Green synthesis, biomedical and biotechnological applications of carbon and graphene quantum dots. A review
}

\author{
Siavash Iravani ${ }^{1} \cdot$ Rajender S. Varma ${ }^{2}$
}

Received: 8 December 2019 / Accepted: 1 March 2020 / Published online: 10 March 2020

C) Springer Nature Switzerland AG 2020

\begin{abstract}
Carbon and graphene quantum dots are prepared using top-down and bottom-up methods. Sustainable synthesis of quantum dots has several advantages such as the use of low-cost and non-toxic raw materials, simple operations, expeditious reactions, renewable resources and straightforward post-processing steps. These nanomaterials are promising for clinical and biomedical sciences, especially in bioimaging, diagnosis, bioanalytical assays and biosensors. Here we review green methods for the fabrication of quantum dots, and biomedical and biotechnological applications.
\end{abstract}

Keywords Quantum dots · Carbon dots · Graphene quantum dots · Biomedical applications · Cancer · Diagnosis · Bioimaging $\cdot$ Biotechnological applications $\cdot$ Sustainable synthesis

\section{Introduction}

Carbonaceous and carbon-based nanomaterials have been attracting a significant research interest because of their exclusive characteristics, including good biocompatibility, non-toxicity, high mechanical/thermal properties, and relative ease of functionalization (Iravani 2011; Iravani and Varma 2019a, b; Mohammadinejad et al. 2016, 2019; Varma 2012, 2014a, b, 2016, 2019). Carbon dots are referred to as fluorescent carbon due to their strong characteristics which up on comparison with the traditional fluorescent dyes exhibit superior fluorescence including photostability, resistance to photobleaching and non-blinking (Xu et al. 2004). Additionally, carbon dots have promising characteristics, including water solubility, low toxicity, high chemical stability, easy derivatization. Due to all these unique traits, carbon dots have found important and widespread

Siavash Iravani

siavashira@gmail.com

$\triangle$ Rajender S. Varma

Varma.Rajender@epa.gov

1 Faculty of Pharmacy and Pharmaceutical Sciences, Isfahan University of Medical Sciences, Isfahan, Iran

2 Department of Physical Chemistry, Faculty of Science, Regional Centre of Advanced Technologies and Materials, Palacký University in Olomouc, Šlechtitelů 27, 78371 Olomouc, Czech Republic applications in biotechnology, energy, catalysis, biological labeling, bioimaging, and gene/drug delivery (Fig. 1 and Table 1) (Baker and Baker 2010; Shen et al. 2012; Cao et al. 2007; Yang et al. 2009a; Wang et al. 2013b). For instance, thermally reduced carbon dot-based fluorescence resonance energy transfer sensor was fabricated for sensitive, costeffective, simple, and selective determination of vitamin B12 ( 1-12 $\mathrm{g} \mathrm{m} \mathrm{ml}^{-1}$ ) in aqueous solutions (Wang et al. 2015a). Additionally, uniform oxygen and sulfur co-doped graphitic carbon nitride quantum dots were produced with significant blue photoluminescence, and good stability which can be applied for cellular imaging with acceptable biocompatibility, and exhibited potential as fluorescent probe for bioimaging and biosensing purposes (Lu et al. 2015).

Carbon dots are traditionally defined as a class of core-shell composites comprising a carbon core and surface passivation with various functional groups, including hydroxyl, carboxyl, and amine, etc., which renders them hydrophilic and facilitate various surface functionalization and passivation. Surface passivation is usually attained by the production of a thin insulating layer of oligomeric polyethylene glycol on an acid-treated carbon dot surface; high fluorescence intensities and high quantum yield of carbon dots can be achieved with an effective surface passivation (Lim et al. 2015). For instance, carbon quantum dots were prepared with quantum yields as high as $60 \%$ via passivation with polyethylene glycol ${ }_{1500 \mathrm{~N}}$ (Wang et al. 2010). Additionally, polyethylenimine (Liu et al. 2012), boronic acid (Shen 


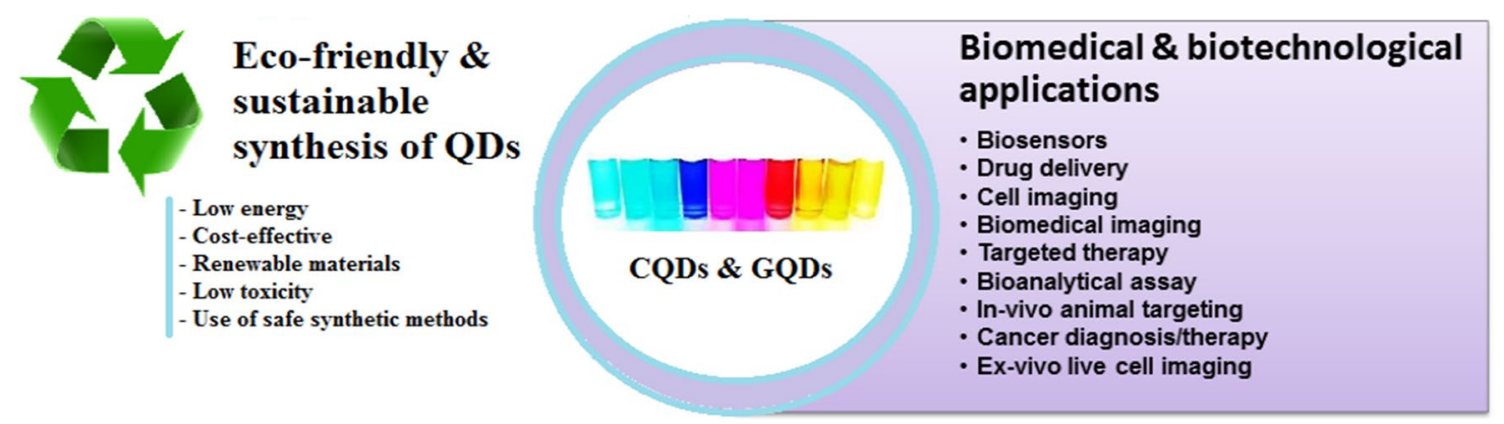

Fig. 1 Sustainable and eco-friendly syntheses of quantum dots as well as their important biomedical and biotechnological applications. QDs: quantum dots, CQDs: Carbon quantum dots, GQDs: Graphene quantum dots

and Xia 2014), $\mathrm{NH}_{2}$-polyethylene-glycol and N-acetyl- ${ }_{\mathrm{L}}$ cysteine (Gonçalves et al. 2010) have been applied for functionalizing carbon dots for application in gene delivery and bioimaging, blood sugar sensing and $\mathrm{Hg}$ (II) sensing (Liu et al. 2016).

Post-synthetic modifications of carbon dots are crucial as the introduction of functional groups, such as amines and carboxyl's, can impose various defects on the carbon dot surface which operate as excitation energy traps and lead to large variations in fluorescence emissions. Surface passivation with functional groups not only produces the surface defects from which the fluorescence originates but also provides potential reactive sites for modification reactions envisioned for specific tasks. By applying these reactive groups, a variety of specific organic, polymeric, inorganic and biomaterials can be affixed to the surfaces of carbon dots through covalent and hydrogen bonds and electrostatic interactions, serving as platforms for specific sensing, drug delivery and other explicit tasks (Liu et al. 2016).

Carbon and graphene quantum dots exhibit astounding attributes to current electrochemical biosensing because of their remarkable solubility in various solvents, intrinsic low toxicity, high electronic characteristics, strong chemical inertness, large specific surface area, availability of abundant edge sites for functionalization, significant biocompatibility, low cost, and versatility, as well as their ability to be altered with significant surface chemistries including nanostructured materials (Campuzano et al. 2019). These quantum dots can be applied as signal tags or electrode surface modifiers to produce electrochemical biosensing (Campuzano et al. 2019).

Various chemical precursors have been detected for generating carbon dots, including ammonium citrate (Fang et al. 2017), ethylene glycol (Jaiswal et al. 2012), citric acid (Schneider et al. 2017), ethylene diamine tetra acetic acid (EDTA) (Liu et al. 2017a), phytic acid (Wang et al. 2013d), phenylenediamine (Vedamalai et al. 2014), thiourea (Wang et al. 2016a), carbon nanotube (Shinde and Pillai 2012) and graphite (Joseph and Anappara 2017). Meanwhile, diverse green carbon precursors have been applied for the production of carbon dots including fruits, their juices and fruit peels (Mehta et al. 2015), animal and animal-derived materials such as chicken egg (Zhang et al. 2015c) and silkworm (Feng et al. 2016), vegetables and spices (Yin et al. 2013), waste kitchen materials like frying oil (Xu et al. 2015) or waste paper (Wei et al. 2014), plant leaves and derivatives (Feng et al. 2015b), among others. Additionally, graphite, nanodiamond, carbon nanotube and active-carbon can be applied as precursor for fabrication of carbon dots (Das et al. 2018).

Generally, carbon dots can be fabricated using top-down and bottom-up strategies (Fig. 2) (Sharma and Das 2019; Wang and $\mathrm{Hu} 2014$ ). The top-down approaches, by which carbon dots are generally formed through the chemical or physical cutting procedures of relatively microscopic carbon structures, comprise arc discharge (Xu et al. 2004), laser ablation/passivation (Yang et al. 2009b; HU et al. 2009a, 2009b; Li et al. 2010b), electrochemical synthesis, (Ming et al. 2012; Zhou et al. 2007), and chemical oxidation (Qiao et al. 2010); most common representative sources for these techniques being carbon nanotube and graphite. Some drawbacks of top-down approaches for synthesizing carbon quantum dots are the requirements of expensive materials and setups, harsh reaction conditions, and longer reaction times (Sharma and Das 2019).

In bottom-up approaches, carbon dots are transformed from suitable molecular precursors under certain conditions exemplified by combustion/thermal/hydrothermal (Zhang et al. 2017; Liu et al. 2007) and microwave/ultrasonic irradiation (Tang et al. 2012; Wang et al. 2011b; Li et al. 2011) wherein the precursors exhibit lower requirements of carbon sources. Additionally, the other preparative strategies have been suggested, including plasma treatment (Jiang et al. 2009), supported synthesis (Bourlinos et al. 2008; Liu et al. 2009; Zong et al. 2011), solution chemistry approaches (Wang et al. 2011a; Hamilton et al. 2011; Mueller et al. 2010; Liu et al. 2011), and cage-opening of fullerenes (Lu et al. 2011). The produced carbon dots, regardless of their 
Table 1 Examples of carbon dots with key applications

\begin{tabular}{|c|c|c|c|c|}
\hline Sources & Synthetic approaches & Size $(\mathrm{nm})$ & Applications & References \\
\hline Apple juice & Hydrothermal & 4.5 & $\begin{array}{l}\text { Imaging of mycobacterium and } \\
\text { fungal cells }\end{array}$ & (Mehta et al. 2015) \\
\hline Bee pollens & Hydrothermal & $1-2$ & Cellular imaging and catalysis & (Zhang et al. 2015b) \\
\hline Beer & Gel filtration chromatography & 2.5 & $\begin{array}{l}\text { Breast cancer cell imaging and } \\
\text { drug delivery }\end{array}$ & (Wang et al. 2015c) \\
\hline Bloomed algae & Microwave & 8 & In vitro imaging & (Ramanan et al. 2016) \\
\hline Carrot & Hydrothermal & 2.3 & Drug delivery & (D'souza et al. 2018) \\
\hline Chionanthus retusus & Hydrothermal & 5 & $\begin{array}{l}\text { Metal ion sensing and imaging of } \\
\text { fungal cells }\end{array}$ & (Atchudan et al. 2017) \\
\hline Coriander leaves & Hydrothermal & 2.4 & $\begin{array}{l}\text { Sensoring of } \mathrm{Fe}^{3+} \text { and cellular } \\
\text { imaging }\end{array}$ & (Sachdev and Gopinath 2015) \\
\hline Date kernel & Hydrothermal & 2.5 & $\begin{array}{l}\text { Sensing of drugs and cellular } \\
\text { imaging }\end{array}$ & (Amin et al. 2018) \\
\hline Food waste-derived & Ultrasonic & 4.6 & In vitro bioimaging & (Park et al. 2014) \\
\hline Garlic & Hydrothermal & 11 & $\begin{array}{l}\text { Cellular imaging and free radical } \\
\text { scavenging }\end{array}$ & (Zhao et al. 2015) \\
\hline Glycerin and polyethylene glycol & Microwave & $3-4$ & Nitrite sensing & (Lin et al. 2011) \\
\hline Grape seed & Microwave & $1-8$ & Nucleus imaging and $\mathrm{pH}$ sensing & (Kumawat et al. 2017a) \\
\hline Honey & Solvothermal & 2 & $\begin{array}{l}\text { Sensing } \mathrm{Fe}^{+3} \text { and imaging of } \\
\text { Hep- } 2 \text { and Hela cells }\end{array}$ & (Yang et al. 2014) \\
\hline Kidney beans & Hydrothermal & $20-30$ & Cellular imaging & (Tripathi et al. 2017) \\
\hline Latex & Microwave & $2-8$ & $\begin{array}{l}\text { Metal sensing and cellular imag- } \\
\text { ing }\end{array}$ & (Balajia et al. 2018) \\
\hline Lemon juice & Hydrothermal & 50 & Optoelectronics and bioimaging & (Hoan et al. 2019) \\
\hline Lignin biomass & Ultrasonic and hydrothermal & $2-6$ & Cellular imaging & (Ding et al. 2018) \\
\hline Lotus root & Microwave & 9.41 & $\begin{array}{l}\text { Heavy metal ion detection and } \\
\text { cellular imaging }\end{array}$ & (Gu et al. 2016) \\
\hline Mango leaves & Microwave & $2-8$ & $\begin{array}{l}\text { Cellular imaging and Temperature } \\
\text { sensors }\end{array}$ & (Kumawat et al. 2017b) \\
\hline Mangosteen pulp & Hydrothermal & 5 & $\begin{array}{l}\text { Sensoring of } \mathrm{Fe}^{3+} \text { and cellular } \\
\text { imaging }\end{array}$ & (Yang et al. 2017a) \\
\hline Onion waste & Hydrothermal & 15 & $\begin{array}{l}\text { Sensoring of } \mathrm{Fe}^{3+} \text { and cellular } \\
\text { imaging }\end{array}$ & (Bandi et al. 2016) \\
\hline Papaya juice & Hydrothermal & 3 & Cellular imaging & (Kasibabu et al. 2015) \\
\hline Prunus mume & Hydrothermal & 9 & Cellular imaging & (Atchudan et al. 2016b) \\
\hline Prunus persica & Hydrothermal & 8 & $\begin{array}{l}\text { Cellular imaging and oxygen } \\
\text { reduction reaction }\end{array}$ & (Atchudan et al. 2016a) \\
\hline Pseudo-stem of banana & Hydrothermal & $1-3$ & $\begin{array}{l}\text { Sensing } \mathrm{Fe}^{+3} \text {, Imaging of Hela and } \\
\text { MCF-7 cells }\end{array}$ & (Vandarkuzhali et al. 2017) \\
\hline Saccharum officinarum & Hydrothermal & 3 & $\begin{array}{l}\text { Cellular imaging of bacteria and } \\
\text { yeast }\end{array}$ & (Mehta et al. 2014) \\
\hline Strawberry & Hydrothermal & 5.2 & $\begin{array}{l}\text { Fluorescent probes for mercury } \\
\text { ions detection }\end{array}$ & (Huang et al. 2013) \\
\hline Sugarcane molasses & Hydrothermal & 1.9 & $\begin{array}{l}\text { Sensoring of } \mathrm{Fe}^{3+} \text { and cellular } \\
\text { imaging }\end{array}$ & (Huang et al. 2017) \\
\hline Sweet potato & Hydrothermal & 3.39 & $\mathrm{Fe}^{+3}$ sensing and cellular imaging & (Shen et al. 2017) \\
\hline Tissue paper & Microwave & 4.2 & Determination of Glutathione & (Sivasankaran et al. 2017) \\
\hline Trapa bispinosa peel & Hydrothermal & $5-10$ & Cellular imaging & (Mewada et al. 2013) \\
\hline Walnut shell & Hydrothermal & 3.4 & Cellular imaging & (Cheng et al. 2017) \\
\hline Water Chestnut and onion & Hydrothermal & 3.5 & $\begin{array}{l}\text { Sensing of } \mathrm{Cu} \text { (II) and Imaging of } \\
\text { Coenzyme A }\end{array}$ & (Hu et al. 2017) \\
\hline Winter melon & Hydrothermal & $4.5-5.2$ & Cellular imaging & (Feng et al. 2015a) \\
\hline
\end{tabular}




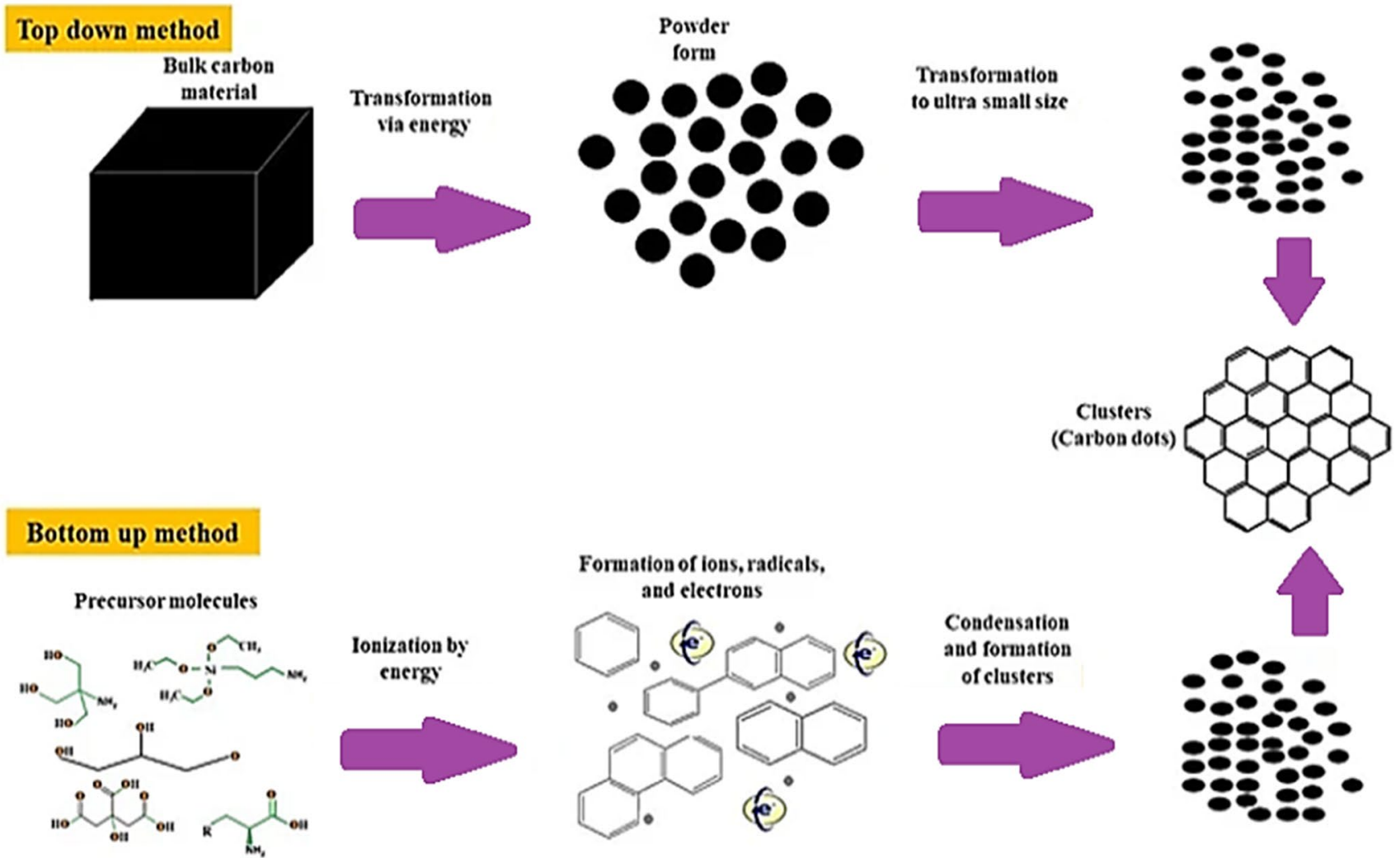

Fig. 2 Carbon dots produced using top-down and bottom-up approaches. Adapted with permission from Sharma and Das (2019)

production techniques, have a mix of sizes, which needs complex separation techniques to obtain mono-dispersed carbon dots. Some of the explored post-synthesis separation techniques include dialysis (Liu et al. 2007), chromatography (Li et al. 2010a; Vinci et al. 2012), gel electrophoresis (Tao et al. 2012), and ultra-filtration (Zheng et al. 2013).

In this critical review, eco-friendly and sustainable fabrication of carbon and graphene quantum dots as well as their important biomedical and biotechnological applications are highlighted. The pros and cons and critical issues pertaining to the deployment of sustainable and eco-friendly strategies for manufacturing these quantum dots, with inherent advantages including non-toxicity, environmental friendliness, novelty, simplicity, greenness and cost-effectiveness, are discussed.

\section{Carbon and graphene quantum dots with diverse unique properties}

Generally, carbon dots can be classified in two main groups, carbon and graphene quantum dots. The graphene quantum dots are anisotropic, with lateral dimensions larger than the height, and possess the crystalline structure of single or a few graphene layer and connected via chemical groups on the edges with circular or elliptical shape. In contrast, carbon quantum dots are always spherical and carbon dots are divided into carbon nanoparticles without a crystal lattice; carbon quantum dots possessing an obvious crystal lattice with $\mathrm{sp}^{2} / \mathrm{sp}^{3}$ carbons (Lin and Zhang 2012; Nie et al. 2014).

All carbon dots have chemical groups on the surface, such as oxygen- or amino-based groups, and polymer chains and these functional groups play a pivotal role in the photoluminescence behavior. Both carbon and graphene quantum dots are effective in photon-harvesting in short-wavelength region because of $\pi-\pi^{*}$ transition of $\mathrm{C}=\mathrm{C}$ bonds. They typically exhibit strong optical absorption in the ultraviolet region ( 260-320 nm), with a tail extending into the visible range. The absorption located in $230-270 \mathrm{~nm}$ is typically attributed to $\pi-\pi^{*}$ transition of $\mathrm{C}=\mathrm{C}$ bonds, and the peak/shoulder located around $300-390 \mathrm{~nm}$ is ascribed to $n-\pi^{*}$ transition of $\mathrm{C}=\mathrm{O}$ bonds. Generally, carbon quantum dots are relatively more efficient in absorption of long wavelengths and have low quantum yield, thus requiring a surface passivation layer for improvement of their brightness. In comparison, graphene quantum dots usually offer higher quantum yield compared to carbon dots because of their layered structure and better crystallinity (Zheng et al. 2015; Zhu et al. 2015). Differently colored carbon dots have been synthesized, ranging from ultraviolet to red, and most commonly, blue and 
green. Undesirable for multi-color imaging, most of these carbon dots display broad emission spectra because of the large heterogeneity (in size and chemical composition) originating from poorly controllable synthesis processes (Zheng et al. 2015).

\section{Optical characteristics}

Typically, carbon and graphene quantum dots with diverse structures have quite similar optical characteristics in terms of their optical fluorescence, absorption, chemiluminescence, electrochemiluminescence, phosphorescence, upconversion photoluminescence, and photo-induced electron transfer property. These materials have attracted immense attention due to their remarkable tunable optical characteristics, cost-effectiveness, simple fabrications and low toxicity, which makes them ideal candidates for optical sensors ( $\mathrm{Li}$ et al. 2019).

Electrochemiluminescence activities are partly responsive to surface passivation, wherein the surface-passivated carbon quantum dots displayed weak electrochemiluminescence activities but strong fluorescence (Dong et al. 2010). Methyl parathion sensors were generated from tyrosine methyl ester functionalized carbon dots via a hydrothermal reaction using citric acid as carbon resource; functionalized carbon dots display strong and stable photoluminescence with a quantum yield of $3.8 \%$ and could be deployed for the determination of assorted organophosphorus compounds (Hou et al. 2015a). Furthermore, alterations in fluorescence of carbon quantum dots were applied for detecting various numbers of inorganic molecules (Pooja et al. 2017). As an example, the detection of $\mathrm{NO}_{2}$ gas was achieved by using quantum dot-functionalized aerogels as the sensing probes wherein they revealed significant fluorescence activities in the solid state. The fluorescence was quenched by $\mathrm{NO}_{2}$ gas, while no quenching was detected when the carbon quantum dot-functionalized aerogels were exposed to a pure nitrogen atmosphere (Wang et al. 2013c).

\section{Biocompatibility properties}

Remarkable biocompatibility and low toxicity are critical for biological and biomedical appliances of carbon and graphene quantum dots, particularly in bioimaging and cellular imaging ( $\mathrm{Li}$ et al. 2019). For instance, in vitro studies have revealed the low cytotoxicity of graphene quantum dots, which was credited to their significant oxygen content and ultra-small size. Additional in vivo biodistribution assay using mice showed no graphene quantum dots accumulations in the main organs and fast clearance of graphene quantum dot via kidney. Notably, injections with graphene quantum dot and graphene oxide showed that graphene quantum dots had no noticeable influences on mice; differently, the graphene oxide revealed some toxicity, even initiating death because of the in vivo aggregations of graphene oxide. In another study, the effect of functional groups on the cytotoxicity of graphene quantum dots was ascertained by comparing their ability to generate reactive oxygen species. Consequently, it was revealed that ketonic carbonyl groups had noticeable effect on reactive oxygen species formation ability of graphene quantum dots. Thus, removing oxygen functional groups on graphene quantum dots could improve the photostability and reduce the cytotoxicity, which provided molecular level indication for the better design of biocompatible graphene quantum dots. Because of their remarkable biocompatibility, graphene quantum dots with a large number of oxygencontaining groups were effectively applied as operative nano-radio-sensitizer for radiotherapy.

Graphene quantum dots could noticeably improve the sensitivity of colorectal carcinoma cells toward ionizing irradiation. Additional investigations showed that the graphene quantum dots in combination with ionizing radiation could evidently suppress the cell proliferation, accelerate apoptosis, and increase the G2/M stage arrest of the cells. Principally, because of the overproduction of reactive oxygen species by graphene quantum dots in synergy with the ionizing radiation, they can activate the apoptosis-related regulation proteins culminating in tumor cell apoptosis (Zhou et al. 2017; Yuan et al. 2014).

\section{Biosensors}

There are a limited number of studies pertaining to biosensing via the deployment of carbon and graphene quantum dots, but future investigations are expected to increase in this arena (Shi et al. 2015b). As an example, graphene quantum dots in combination with gold nanoparticles were applied for developing the fluorescence resonance energy transfer biosensors for identifying a specific gene sequence from Staphylococcus aureus (Shi et al. 2015b). Further, well-defined modifications of graphene quantum dots have been applied in biosensors preparation. The resulting fluorescent intensity change produced a signal for target microRNA detection with satisfied discrimination abilities in a wide detection range from 0.1 to $200 \mathrm{nM}$, offering an approach for detection of microRNA based on graphene quantum dots (Zhang et al. 2015a). Additionally, carbon and graphene quantum dots can be applied for fabricating of immuno-sensor. For instance, an immuno-sensor was prepared for 8-hydroxy-2'-deoxyguanosine (8-OHdG) where carbon quantum dots coated with gold $/ \mathrm{SiO}_{2}$ coreshell nanoparticles were immobilized onto a platinum electrode (Zhou et al. 2015). 


\section{Carbon quantum dots}

Carbon quantum dots are category of carbon nanostructures which have received extensive consideration owing to their unique properties comprising significant photostability, high solubility in water, non-toxicity, good biocompatibility, chemical inertness and high resistance to photobleaching. Furthermore, their optical properties can be fine-tuned by size control, chemical doping and functionalization for required applications, including gene delivery, bioimaging, optronics, drug delivery, sensing, and catalysis (Sachdev and Gopinath 2015; Yang et al. 2017a; Barras et al. 2016; Nekoueian et al. 2019; Li et al. 2015).

It has been shown that carbon quantum dots, which could serve as peroxidase mimetics, demonstrate an excellent catalytic activity for the decomposition of $\mathrm{H}_{2} \mathrm{O}_{2}$. Liu et al. reported that photoactive metal-free carbon quantum dot-carbon nitride nanocomposites break down the peroxide (Liu et al. 2015a). These results provide a notion to help develop carbon quantum dot-containing hybrid semiconductors for resolving toxic issues during the water splitting process. In addition to bioimaging and biosensor applications, carbon quantum dots have been investigated for antibacterial, anti-inflammatory, and also for photodynamic therapy applications. In view of the increasing biomedical and clinical applications of carbon quantum dots, a better understanding of their safety when exposed to blood stream is the need of the hour. Determination of hemolytic properties is one of the fundamental tests in studies of nanoparticles' interaction with blood components and cardiovascular system. Hemolysis may occur when the red blood cell membrane is ruptured and releases hemoglobin into blood plasma which may lead to anemia, hypertension, and renal toxicity. It is therefore imperative to study the hemotoxicity of all nanoparticles that would be administered intravenously. Recently, a special chemical cleavage of layered $\mathrm{N}$-doped carbon materials, carbon nitride quantum dots, was proposed (Cao et al. 2007; Yang et al. 2009a; Wang et al. 2013b).

The facile electrochemical fabrication of water-soluble carbon quantum dots has been achieved using an alkalibase electrolyte requiring chemicals/surface passive agents, and complex instrumental setups or post-treatments. Indeed, carbon quantum dots could be prepared by traditional approaches, including electrochemical oxidation, laser ablation, hydrothermal/solvothermal treatment, microwave irradiation and arc discharge, thermal cracking of organic compounds, pyrolysis and oxidation of candle soot. These protocols have disadvantages namely involvement of sophisticated instruments, strong acids for selfpassivation and tedious procedures. Recently, synthesis of self-passivated fluorescent carbon quantum dots by hydrothermal carbonization of materials has been reported in a single step using various biomass namely deploying ascorbic acid, gelatin, citric acid, egg albumin, bovine serum albumin, orange juice, honey, chitosan, cow milk, soy milk, banana, coffee seeds, watermelon peels, pomelo peel, grass, cellulose, starch, food caramels, and paper ash as carbon source (Cao et al. 2007; Yang et al. 2009a; Wang et al. 2013b). These carbon quantum dots display characteristic fluorescence depending upon the functionalities present on the surface. Moreover, hydrothermal carbonization is a greener approach with the use of renewable biomass as a carbon source and at low reaction temperatures; both carbonization and functionalization can be achievable in a single step (Cao et al. 2007; Yang et al. 2009a; Wang et al. 2013b).

\section{Eco-friendly and sustainable synthesis of carbon quantum dots}

Green chemistry is the engagement of important principles which reduces or eliminates the application or generation of hazardous substances in the design, manufacture, and application of chemical products; none or less hazardous chemical synthesis, applying safer and non-toxic chemicals, solvents and processes are some of them (Varma 2014b, 2016); as an example, bio wastes can be applied as sustainable and cost-effective carbon sources for synthesizing carbon quantum dots. In one study, spherical water-soluble carbon quantum dots (about 1-3 nm) have been prepared from lemon peels waste deploying a cost-effective hydrothermal strategy; the ensuing stable carbon quantum dots were found to be oxygen-rich in surface functionalities and the water soluble and exhibited excellent photoluminescence properties with quantum yield about $14 \%$. The prepared carbon quantum dots were used to design an economic, green and highly sensitive fluorescent probe for the detection of $\mathrm{Cr}^{6+}$ ions with a detection limit of about $73 \mathrm{nM}$; water-soluble carbon quantum dots-based fluorescent probe could be used as a simple, rapid, convenient technique for the sensitive and selective detection of $\mathrm{Cr}^{6+}$ in water purification processes. Moreover, carbon quantum dots have been immobilized over electrospun $\mathrm{TiO}_{2}$ nanofibers and the emanating photocatalytic activity for such a $\mathrm{TiO}_{2}$-water-soluble carbon quantum dots composite was reported using methylene blue dye as a model pollutant; the photocatalytic activity being about 2.5 times more than that of titanium dioxide nanofibers (Tyagi et al. 2016).

A greener synthesis of water-soluble fluorescent carbon quantum dots $(\sim 260-400 \mathrm{~nm})$ was reported via a simple one-step hydrothermal treatment using Tamarindus indica leaves; these biocompatible carbon quantum dots can be potentially applied in sensing, bioimaging, disease 
diagnostics, and other analytical applications (Bano et al. 2018). Another facile approach for producing fluorescent carbon quantum dots entails the hydrothermal treatment of pineapples (Ananas comosus) and calamansi (Citrofortunella microcarpa) wastes (de Yro et al. 2019). The Escherichia coli, fluoresced with carbon quantum dots as effective probe, have been applied for bioimaging applications. The generation of hydrogen bonds between the bacterial cells and carbon quantum dots facilitated the attachment of these quantum dots onto the bacteria (de Yro et al. 2019).

Well dispersed carbon quantum dots $(\sim 2-4 \mathrm{~nm})$ have been synthesized by greener ozone oxidation of lignite coal, which is plentiful and cheap, and comprise oxygen-rich functional groups with suitable water-solubility and optical characteristics, and yield reaching 35\% (Liu et al. 2018b). The prepared quantum dots had quenching effects for $\mathrm{Fe}^{3+}$ with remarkable sensitivity and selectivity as well as desirable anti-interference performance wherein the fluorescence intensity of carbon quantum dots showed significant linear responses to the $\mathrm{Fe}^{3+}$ concentrations $\left(10-150 \mu \mathrm{mol} \mathrm{L}{ }^{-1}\right)$ with the detection limit of $0.26 \mu \mathrm{mol} \mathrm{L}^{-1}$ (Liu et al. 2018b). Highly stable and luminescent multi-color carbon quantum dots $(\sim 4.85 \pm 0.07 \mathrm{~nm})$ were produced in one pot using Cydonia oblonga powder as carbon precursors via microwave irradiation which have maximum emission intensity at $450 \mathrm{~nm}$ if excited at $350 \mathrm{~nm}$ with a quantum yield of $8.55 \%$. Carbon quantum dots produced through microwave heating technique in 30 min were compared with those synthesized hydrothermally in a Teflon-linen stainless steel body autoclave at $200{ }^{\circ} \mathrm{C}$ (Ramezani et al. 2018).

Citrus lemon juice as a precursor was applied for the greener synthesis of fluorescent carbon quantum dots $(\sim 2-10 \mathrm{~nm})$ using hydrothermal approach (Tadessea et al. 2018) which showed high photoluminescence of $10.20 \%$ quantum yield; the photoluminescence intensity being depended on $\mathrm{pH}$ of the solution and maximum intensity was obtained at $\mathrm{pH}$ of 6 . It was shown that carbon quantum dots can be used as florescent probe in the cell imaging (Tadessea et al. 2018). In related research, amorphous fluorescent carbon dots from orange waste peels were produced using the hydrothermal carbonization approach at a mild temperature $\left(180^{\circ} \mathrm{C}\right)$ (Prasannan and Imae 2013); their composite with zinc oxide was used as a photocatalyst for the degradation of naphthol blue-black azo dye under ultraviolet irradiation, and the superior photocatalytic activity was discerned (Prasannan and Imae 2013).

Bright green luminescent graphitic carbon nitride quantum dots doped with oxygen and sulfur were produced using microwave treatment of citric acid and thiourea; they displayed excitation wavelength and $\mathrm{pH}$-dependent luminescence behaviors in the visible range. Further, these quantum dots showed high fluorescence quantum yield (31.67\%), strong resistance to the interference of high ionic strength environment, and good biocompatibility as evaluated by the cell viability assay ( $\mathrm{Li}$ et al. 2016). In another study, hydrothermal carbonization of Prunus avium fruit extracts was applied for fabricating fluorescent nitrogen-doped carbon dots $(\sim 7 \mathrm{~nm})$ which exhibited significant fluorescent characteristics and produced blue fluorescence; the green synthesized carbon dots were applied as fluorescent probes for detecting biologically important $\mathrm{Fe}^{3+}$ ions in water with remarkable selectivity and sensitivity, and for bioimaging of the examined cells (Edison et al. 2016b). An expeditious and facile microwave method was introduced for producing fluorescent nitrogen-doped carbon dots which were hydrothermally prepared by applying $L$-ascorbic acid (as the carbon precursor) and $\beta$-alanine (as the nitrogen dopant) with remarkable blue fluorescence and low cytotoxicity. These carbon dots can be applied as staining probes for confocal cellular imaging (Edison et al. 2016a).

Synthesis of mono-dispersed carbon quantum dots via a single-step thermal decomposition method was reported using the fennel seeds (Foeniculum vulgare) (Fig. 3) (Dager et al. 2019); the prepared quantum dots showed significant colloidal, photostability, environmental stability $(\mathrm{pH})$, and did not need extra surface passivation step for improving their fluorescence. Additionally, these particles demonstrated remarkable photoluminescence activity and excitation-independent emission. The effect of some factors like reaction time and temperature on pyrolysis provided insight into the formation of carbon quantum dots; these quantum dots can be applied in biosensing, cellular imaging, lightemitting diode, solar cell, supercapacitor, printing, and sensors (Dager et al. 2019).

Highly photoluminescent carbon dots have been prepared, with a quantum yield of up to $35.3 \%$, at room temperature which can be further separated out into green-emissive amorphous carbon nano-dots and yellow-emissive crystalline graphene quantum dots through a silica gel column. The ensuing carbon dots, even with the same particle-size distribution and chemical groups, have different degrees of surface oxidation (Liu et al. 2017b). Additionally, highly fluorescent carbon quantum dots $(\sim 6 \mathrm{~nm})$ were prepared by the pyrolysis of Eleusine coracana as a carbon source wherein $\mathrm{Cu}^{2+}$ strongly quenched the fluorescent intensity of carbon quantum dots compared to other metal ions; $\mathrm{Cu}^{2+}$ preferentially adsorbed on aromatic CC ( $\pi$-bond) of carbon quantum dots, whereas other divalent metals form $\sigma$-bond(s) with the carbon quantum dots (Murugan et al. 2019).

Carbon quantum dots $(\sim 2.0-6.0 \mathrm{~nm})$ with good biocompatibility, photostability, and sustainability attributes were prepared from by-products derived from a biorefinery procedure using one-pot hydrothermal treatment (Fig. 4) (Huang et al. 2019a). The significant components of by-products were the degradation products (autohydrolyzate) of biomass pretreated by autohydrolysis. The carbon quantum dots 
(a)

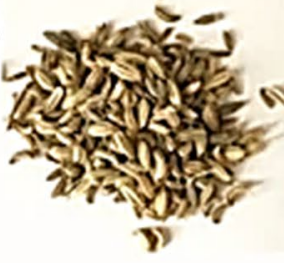

Fennel seeds (b)

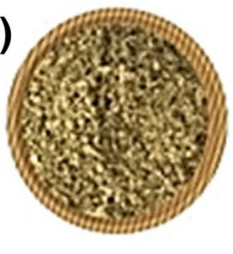

Fennel seeds powder

(g)

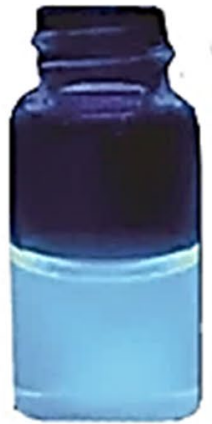

C-QDs Under UV (c)

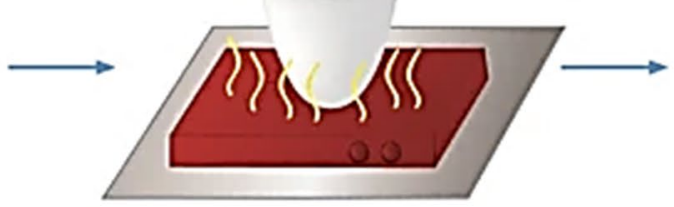

Pyrolysis method at $500 \mathrm{C}$ for $3 \mathrm{hrs}$

(f)

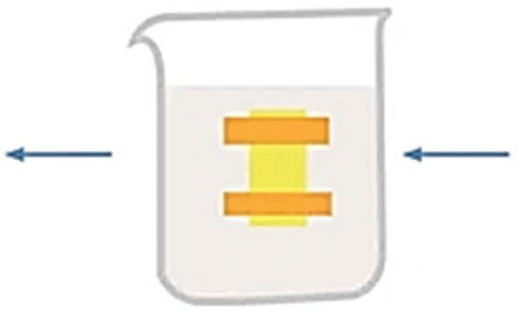

Dialysis

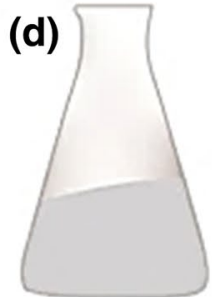

Sonication $10 \mathrm{~min}$

(e)

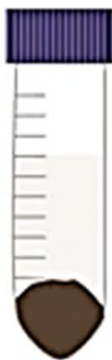

Centrifugation at $5000 \mathrm{rpm}$ for $10 \mathrm{~min}$

Fig. 3 Carbon quantum dots formation from fennel seeds by pyrolysis. a Fennel seeds, b ground fennel powder, c pyrolysis of fennel powder, d sonication of carbon quantum dots, e centrifugation of carbon quantum dots, $\mathbf{f}$ dialysis of carbon quantum dots, $\mathbf{g}$ carbon

quantum dots under ultraviolet, and $\mathbf{h}$ transmission electron micrograph image of carbon quantum dots. Reprinted with permission from Dager et al. (2019)
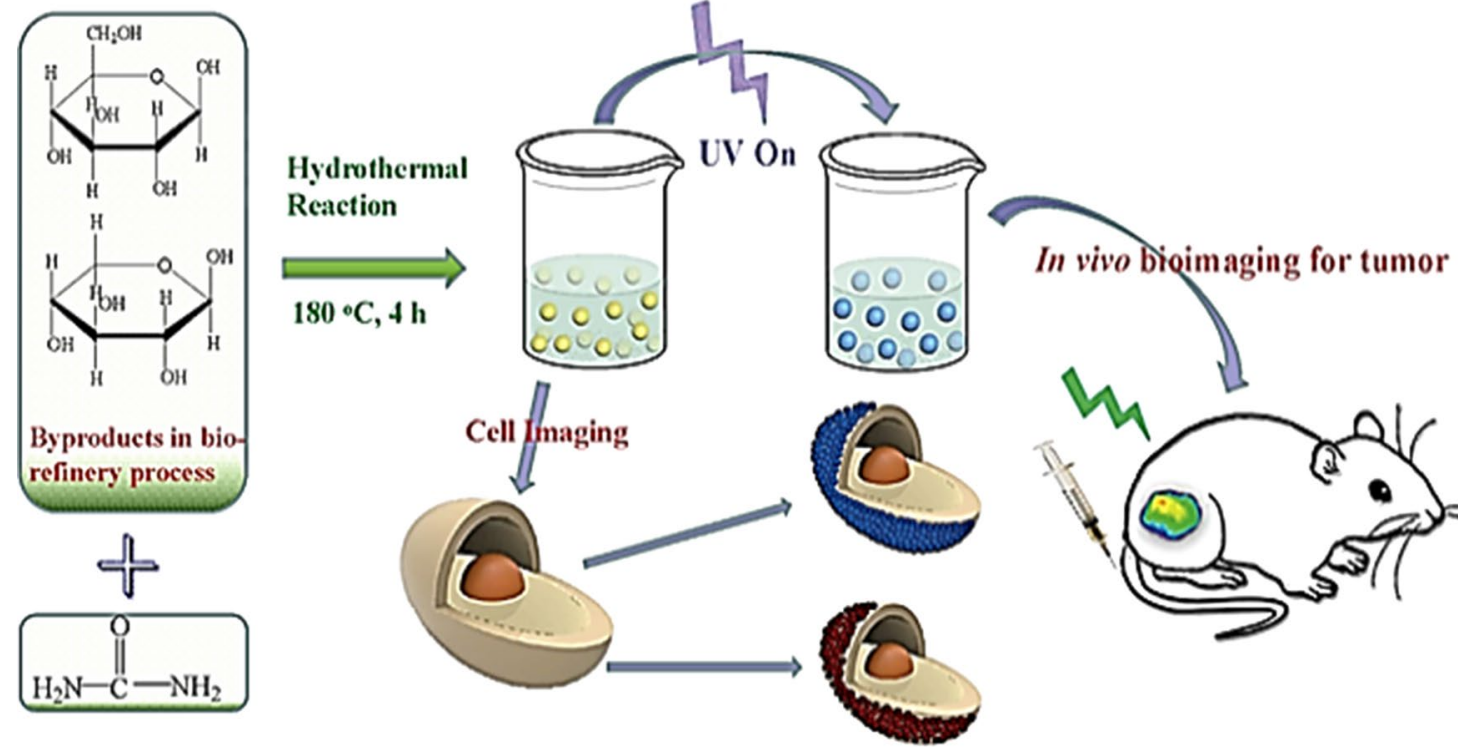

Fig. 4 Green synthesis of carbon quantum dots from biorefinery by-products, as the precursor, with good biocompatibility, photostability and sustainability attributes. Reprinted with permission from Huang et al. (2019a) 
showed blue-green fluorescence with a quantum yield of about $13 \%$, and the fluorescence behaviors were reported to be stable with remarkable resistance to photobleaching and temperature alterations (Huang et al. 2019a).

Low-cost biomass of cyanobacteria was used as the carbon source for producing water-soluble carbon quantum dots by a simple hydrothermal method (Fig. 5) (Wang et al. 2019); the ensuing carbon quantum dots were mono-dispersed (about $2.48 \mathrm{~nm}$ ), and showed excitation-dependent emission performance with a quantum yield of $9.24 \%$. The cyanobacteria-derived carbon quantum dots had almost no photobleaching under long-time ultraviolet irradiation, and exhibited high photostability in the solutions with a wide range of $\mathrm{pH}$ and salinity. Since no additional chemical reagent was involved in their generation, the synthesized carbon quantum dots displayed low cytotoxicity for $\mathrm{PC}_{12}$ cells even at a high concentration. Moreover, the carbon quantum dots could be efficiently taken up by cells to illuminate the whole cell and create a clear distinction between cytoplasm and nucleus (Wang et al. 2019).

A greener hydrothermal synthesis for carbon quantum dots $(\sim 12 \mathrm{~nm}$ ) was reported from walnut oil (Arkan E et al. 2018). The produced carbon quantum dots showed valuable fluorescent quantum yield of $14.5 \%$ with quinine sulfate (quantum yield 54\%) as a reference and significant photo as well as $\mathrm{pH}$ stabilities. The walnut carbon quantum dots were reported to be significantly potent cytotoxic agent, especially against MCF-7 and PC-3 cell lines. The apoptosis induction by carbon quantum dots was convoyed by acceleration in the activation of caspase-3, while caspase- 9 activity did not hasten after exposure to the carbon quantum dots (Arkan E et al. 2018).

Novel types of $N$-doped chitosan-based carbon quantum dots have been achieved with simultaneous $N$-doping using biocompatible amino acids according to "green chemistry" principles (Fig. 6) (Janus et al. 2019). For the carbon quantum dots production, renewable chitosan has been applied with good biocompatibility. In this study, the cytotoxicity evaluations of the carbon quantum dots has been analyzed by 2,3-Bis-(2-methoxy-4-nitro5-sulfophenyl)-2H-tetrazolium5-carboxanilide salt approach; the production of biocompatible quantum dots with carbon cores was recognized, which exhibited luminescence in visible range. It was reported that modifications with lysine (11.5\%) and glutamic acid (7.4\%) had significant effects on quantum yield, but amino acid functionalization did not remarkably influenced the fluorescence characteristics (Janus et al. 2019). In another study, the synthesized spherical carbon quantum dots (with twodimensional structures) from chitosan have been applied as corrosion inhibitors in BIS 2062 carbon steel (Keerthana and
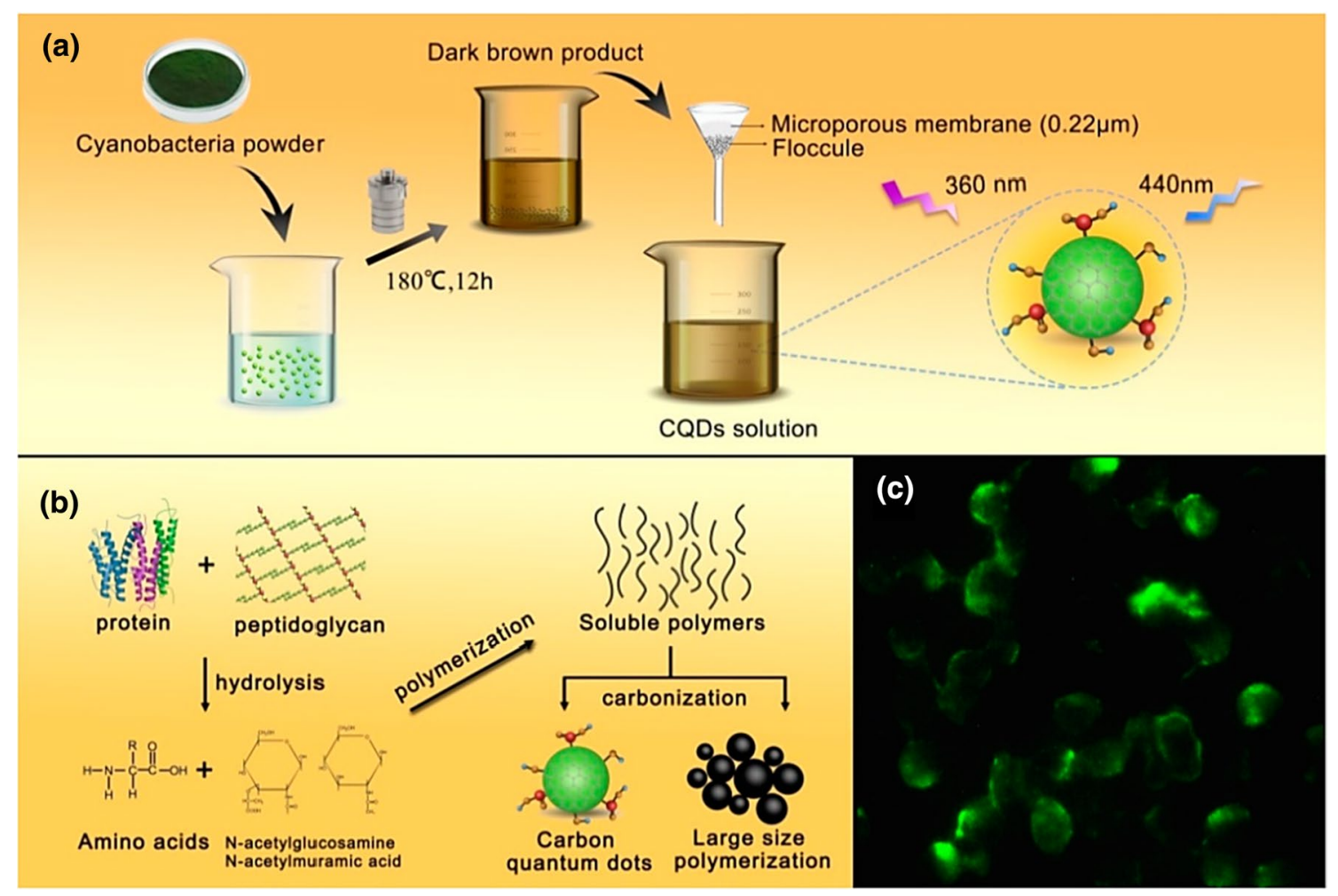

Fig. 5 Synthesis of carbon quantum dots from cyanobacteria: a possible formation procedure of the cyanobacteria-derived carbon quantum dots; b fluorescence image of PC12 cells incubated with carbon quantum dots (c). Reprinted with permission from Wang et al. (2019) 


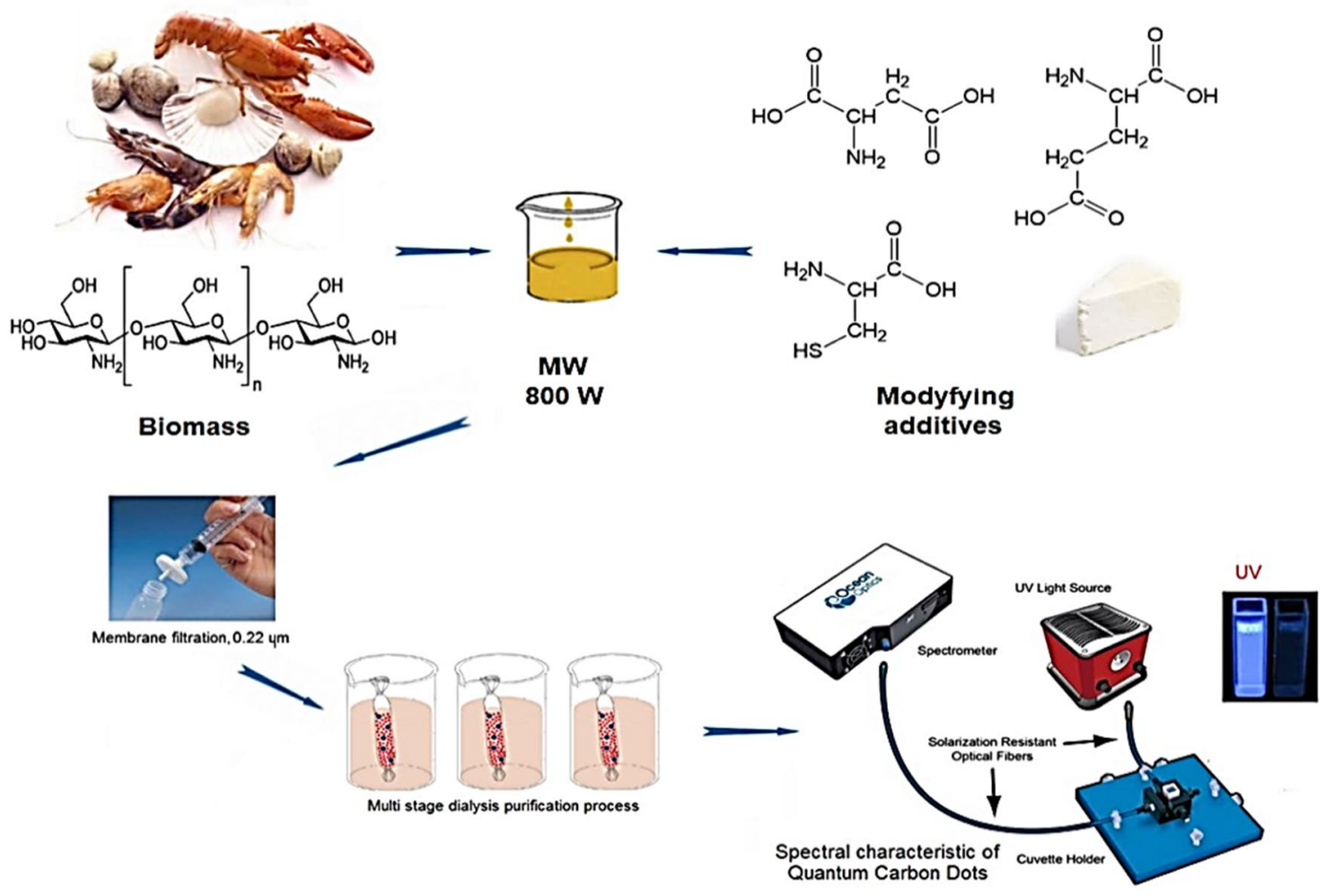

Fig. 6 Green synthesis of $N$-doped chitosan-based carbon quantum dots using chitosan. The prepared quantum dots with carbon cores and good biocompatibility exhibited luminescence in visible range. Reprinted with permission from Janus et al. (2019)

Ashraf 2019). It was revealed that the prepared carbon dots were rich in $\mathrm{C}=\mathrm{O}$ and $\mathrm{C}-\mathrm{O}$ functional groups (Keerthana and Ashraf 2019).

\section{Biomedical and biotechnological applications}

Carbon dots have been deployed for diverse biomedical and biotechnological applications due to their excellent photoluminescence properties as well as the wavelength-tuneable emission property, unique electronic, mechanical, thermal, and chemical properties. In contrast to the traditional quantum dots, essentially comprising heavy metals which have known toxicity and are environmentally hazardous, carbon dots are much safer and non-toxic both in cells and at animal level, suggesting their good environmental and biological compatibility for biomedical and biotechnological applications such as biosensing, bioimaging, gene and drug delivery (Wang et al. 2013a; Baker and Baker 2010).

\section{Sensors}

Various kind of sensors have been designed using carbon dots to detect assorted targets such as DNA (Wang et al. 2013e), heavy metals (Kumar et al. 2017), glucose (Shi et al. 2011), proteins (Dai et al. 2012), $\mathrm{H}_{2} \mathrm{O}_{2}$ (Zhao et al. 2013), nitrite (Lin et al. 2011), and phosphate (Zhao et al. 2011), among others. For instance, carbon dots prepared from flour and electrochemical carbonization of sodium citrate and urea show the photoluminescence emission which could be selectively quenched by $\mathrm{Hg}^{2+}$ with a detection limit of $0.5 \mathrm{nM}$ and $3.3 \mathrm{nM}$, respectively (Qin et al. 2013; Hou et al. 2015b); other heavy metals such as $\mathrm{Sn}^{2+}, \mathrm{Fe}^{3+}, \mathrm{Pb}^{2+}, \mathrm{Cr}^{6+}$, $\mathrm{Mn}^{2+}$ and $\mathrm{Cu}^{2+}$ were also detected (Gogoi et al. 2015; Yazid et al. 2013; Xu et al. 2014). The produced carbon quantum dots showed an excitation-dependent behavior with a high quantum yield of about $46.6 \%$ and could be applied as a very sensitive nanoprobe for the turn-off sensing of $\mathrm{Hg}^{2+}$ with a minimum limit of detection as low as $6 \mathrm{nM}$ in the dynamic range from 0 to $0.1 \mu \mathrm{M}$. Furthermore, it can act as a turnon sensor for glutathione detection with valuable selectivity (Bano et al. 2018).

Boronic acid modified carbon dots have been utilized for non-enzymatic blood glucose sensing wherein the glucose level can be quantified in the range of 9-900 $\mu \mathrm{M}$ with a detection limit of $1.5 \mu \mathrm{M}$; plasma glucose concentration determined by this method is in good agreement with the values measured by a commercial blood glucose monitor (Shen and Xia 2014). Carbon dot-based fluorescence turn-on sensors were instructed for hydrogen peroxide $\left(\mathrm{H}_{2} \mathrm{O}_{2}\right)$ monitoring in aqueous solutions through a photo-induced electron 
transfer mechanism where the sensor showed good selectivity, and sensitivity with a detection limit of $84 \mathrm{nM}$ (Lan et al. 2015). In another study, N, S-co-doped fluorescent carbon nano-dots have been synthesized by applying thermal treatment of ammonium persulfate, ethylenediamine and glucose. They displayed bright blue emission with a remarkable fluorescent quantum yield of $21.6 \%$, approved water solubility, uniform morphology, and significant chemical stability as compared to pure carbon dots. The fluorescence of the produced carbon nano-dots could be remarkably quenched by methotrexate through fluorescence resonance energy transfer between carbon nano-dots and methotrexate, and has been applied for highly selective and sensitive identification of methotrexate (more than $50.0 \mu \mathrm{M}$ ) with a low detection limit of $0.33 \mathrm{nM}$; it can be useful for hands-on finding of methotrexate in human serum (Wang et al. 2015b). Amino-functionalized fluorescent carbon dots have also been prepared by hydrothermal treatment of glucosamine and the ensued carbon dots exhibited stabilized green emission fluorescence at various excitation wavelengths and $\mathrm{pH}$ environments; they can be used to produce biosensors and for selective detection of hyaluronidase (Liu et al. 2015b).

\section{Imaging and bioimaging}

Carbon quantum dots can be applied for tumoral cells imaging, which is suitable for clinical and biological imaging and related diagnostic and therapeutic areas, including phototherapies and diagnostic cancer imaging. For instance, the optical imaging of the carbon quantum dot-wheat straw has been evaluated by intravenous injection of $200 \mu \mathrm{L}$ carbon quantum dot-wheat straw $\left(0.2 \mu \mathrm{g} \mathrm{mL}^{-1}\right)$ into the mouse through the tail vein. Optical images of the carbon quantum dot-wheat straw distributions in the tumor-bearing mouse over increasing times, as well as optical images of fluorescence intensities within the harvested organs can be observed in Fig. 7 (Huang et al. 2019a).

Application of carbon dots as fluorescent labels for cellular imaging has been documented (Sun et al. 2006). Carbon dots are promising candidate for bioimaging purposes because of their low side effects and toxicity, excellent water solubility and visible-to-near infrared (NIR) emission properties (Miao et al. 2015). Various types of cells have been imaged using carbon dots such as Ehrlich ascites carcinoma cells (EACs) (Ray et al. 2009), E. coli (Liu et al. 2009), HepG2 cells (Xu et al. 2013), NIH-3T3 fibroblast cells (Zhang et al. 2013), HeLa cells (Dong et al. 2013), and human lung cancer (A549) (Wu et al. 2013). (Jiang et al. 2014) reported the presence of photoluminescence carbon dots from commercial Nescafe instant coffee with the size of $4.4 \mathrm{~nm}$ and quantum yield about $5.5 \%$; coffee-derived carbon dots have been directly applied in the imaging of carcinoma cells and small guppy fish without functionalization. Carbon (a)
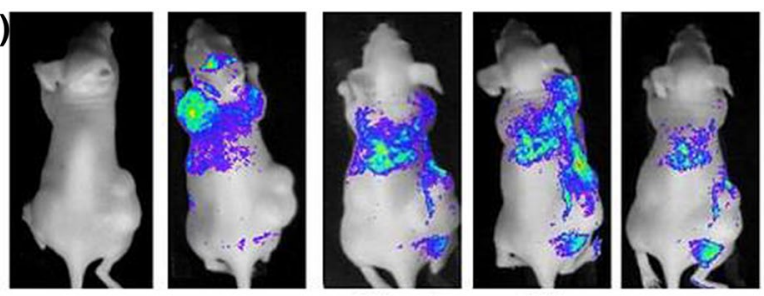

$0 \mathrm{~min}$

5 min
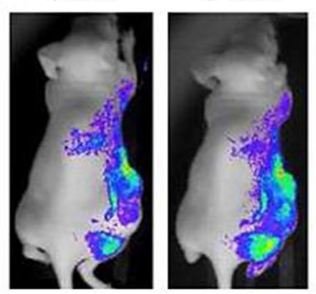

$30 \mathrm{~min}$

$1 \mathrm{~h}$
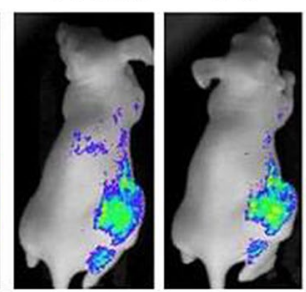

$2 \mathrm{~h}$

$3 \mathbf{h}$
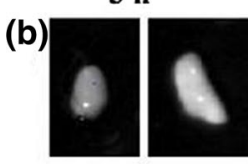

$4 \mathrm{~h}$

$8 \mathrm{~h}$
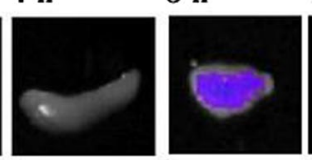

$12 \mathrm{~h}$

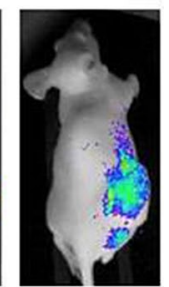

Heart

Lung

Spleen

Kidney

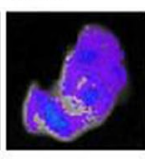

$24 \mathrm{~h}$

Fig. 7 a In vivo fluorescence imaging of nude mice after intravenous injection of carbon quantum dot-wheat straw solution; b representative fluorescence images of dissected organs of a mouse after intravenous injection of carbon quantum dot-wheat straw solution for $24 \mathrm{~h}$. Reprinted with permission from Huang et al. (2019a)

dots passivated with PPEI-EI for two-photon luminescence microscopy were used to image human breast cancer MCF-7 cells (Cao et al. 2007); carbon dots showed bright photoluminescence both on the cell membrane and in the cytoplasm after $2 \mathrm{~h}$ incubation at $37{ }^{\circ} \mathrm{C}$ wherein the cellular uptake of carbon dots was temperature-dependent with no internationalization observed at $4{ }^{\circ} \mathrm{C}$. Zhu et al. (2014) prepared a two-photon "turn-on" fluorescent probe, which was then used for imaging hydrogen sulfide in live cells and tissues.

Ultra-small carbon dots $(0.9 \mathrm{~nm})$ with quantum yield of $47 \%$ have been produced via pyrolysis of anhydrous citric acid in organosilane at $240{ }^{\circ} \mathrm{C}$ for $1 \mathrm{~min}$. The organosilanefunctionalized carbon dots are stable in various non-aqueous solutions and can be directly fabricated into a hybrid fluorescent film or monolith through a simple heating procedure, in the absence of any additional polymers or inorganic compounds. Alternatively, they can be further assembled into silica-encapsulated nanoparticles by hydrolyzing and co-condensing the carbon dots with silica precursors for the bio-labeling and imaging applications (Zou et al. 2015).

\section{Drug and gene delivery systems}

Carbon quantum dots possess excellent drug/gene loading capability in view of their biocompatibility, non-toxicity and photoluminescence properties, where their small size and 
large surface area allow rapid cellular uptake with limited influence on drug activity (Gogoi and Chowdhury 2014; Karthik et al. 2013). Lee et al. (2014) confirmed the delivery of doxorubicin in vitro and in vivo using carbon dots; doxorubicin was loaded on carbon dots via electrostatic interactions with $95 \%$ loading efficiency and induced death of HepG2 and MCF-7 cancer cells as well as tumor in mice. Further, pure carbon dots preferably labeled the nucleus, whereas carbon dots loaded with doxorubicin were mainly distributed in the cytoplasm. A smart stimuli-response drug delivery system comprising carbon dots and alginate was suggested where carbon dots, coated on the surface of alginate beads and garlic extract containing allicin, was taken as model drug system (Majumdar et al. 2016); the amount of garlic extract loaded on alginate beads coated with carbon dots was $60 \%$ higher than uncoated alginate beads. The loaded system displayed $\mathrm{pH}$-dependent controlled drug release, resulting in enhanced therapeutic efficiency depending, interestingly, upon the amount of pathogen present in the target.

A smart carrier was developed for redox-responsive controlled drug delivery by grafting carboxyl-abundant carbon dots to the surface of silica nanoparticles which was found to be pH-dependent (Jiao et al. 2016); doxorubicin loaded on the grafted silica had high drug loading (up to $13.1 \%$ ) and showed a high cellular uptake and an excellent therapeutic effect on cancer cells by 3-(4,5-Dimethylthiazol2-yl)-2,5-diphenyl tetrazolium bromide assay. Additionally, gene delivery has been successfully illustrated with positively charged carbon dots which could be linked to plasmid DNA and efficiently transfect the therapeutic plasmid into cells with high efficiency and low cytotoxicity (Yang et al. 2017b). It has been shown that hyaluronate and polyethylenimine-functionalized carbon dots were internalized readily into the cytoplasm of cancer via hyaluronate-receptormediated endocytosis; the functionalized carbon dots have excellent gene condensation compatibility via electrostatic attraction and protective capacity by preventing nuclease degradation (Zhang et al. 2017).

\section{Antimicrobial and antiviral effects}

Carbon quantum dots are capable of effectively interacting with viruses and block-viral infectivity (Barras et al. 2016), as exemplified by carbon quantum dots functionalized with boronic acid and/or amine functions which interfere with the entry of the herpes simplex virus type 1 (Barras et al. 2016); carbon quantum dots prepared from 4-aminophenylboronic acid hydrochloride, via an altered hydrothermal carbonization procedure, prevent herpes simplex virus type 1 infection, whereas carbon quantum dots emanating from phenylboronic acid demonstrated no effects even at elevated concentrations. These carbon quantum dots can be applied as therapeutic options for extremely pathogenic human coronavirus infections; mechanistically, it may be due to the human coronavirus-229E entrance inhibition, because of the interaction of the boronic acid functions of carbon quantum dots with the HCoV-229E S protein through pseudo-lectin-based interactions. These findings inspired researchers to substitute presently applied antiviral agents (such as ribavirin and interferons), recognized to have major side effects, including short-term memory loss, deficits in decision-making functions, confusion, and extrapyramidal influences. More explorations should be undertaken for investigating the clinical effects of these nanostructures as alternative therapeutics and approaches to confront the severe and life-threatening diseases (Nekoueian et al. 2019).

Carbon dots can be applied for microbial imaging and evaluations, as well as killing of infectious organisms like $E$. coli, S. aureus, Pseudomonas aeruginosa and Candida albicans. These carbon dots can be applied in microbial detection, microbial viability assessments, gram-type identification, and biofilm imaging (Priyadarshini et al. 2018; Habiba et al. 2015; Lin et al. 2019). Interestingly, the carbon dots platform has been harnessed fundamentally as a carrier for conventional disinfection agents to destroy bacteria, and also as a fluorescence label for analyzing the dead bacterial cells. Apparently, these carbon dots could selectively interact with the Grampositive bacteria, get adsorbed, and their fluorescence emission being accelerated remarkably. The carbon dot adsorption could destruct the bacterial cell surface, as these carbon dots changed the charge balance of the bacterial surface and were inserted into the bacterial surface through the long alkyl chains leading to the bacterial inactivation. This carbon dot-based differentiation method has been fast, accurate, and easy to operate (Fig. 8) (Yang et al. 2019b).

\section{Pharmaceutical formulations}

Carbon quantum dots $(\sim 6 \mathrm{~nm})$ which have been prepared from carbon powder by acid treatment at elevated temperatures were capable of effectively inhibiting insulin fibrillation in a concentration-dependent manner (about $0.2 \mu \mathrm{g} \mathrm{mL}^{-1}$ ). Additionally, carbon quantum dots $\left(40 \mu \mathrm{g} \mathrm{mL}^{-1}\right)$ prevented $0.2 \mu \mathrm{g} \mathrm{mL}^{-1}$ of human insulin from fibrillation for 5 days under $65^{\circ} \mathrm{C}$, whereas insulin denatures in $3 \mathrm{~h}$ under the same conditions without carbon quantum dots. Therefore, these carbon quantum dots have the potentials to inhibit insulin fibrillation in bio-systems and in the pharmaceutical industry for the processing and formulation of insulin ( $\mathrm{Li}$ et al. 2015). 


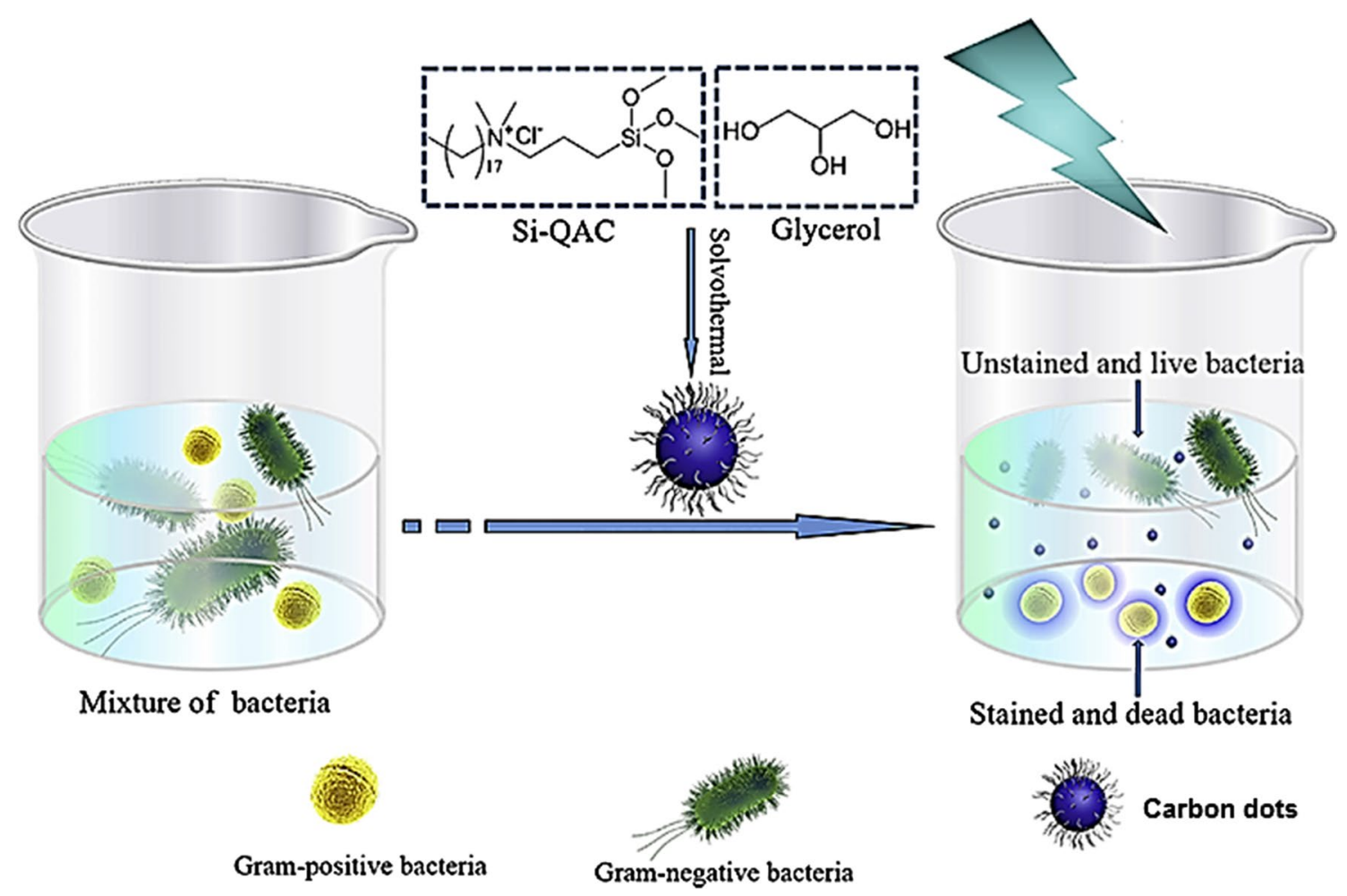

Fig. 8 Quaternized carbon dots production and their potentials for selective imaging and killing of Gram-positive bacteria. Adapted with permission from Yang et al. (2019b)

\section{Graphene quantum dots}

Graphene quantum dots have garnered remarkable attention because of their unique properties, including tunable photoluminescence properties, significant photostability, hydrophilic nature, low toxicity, and good biocompatibility. They have promising biological, biomedical applications, and can be applied in diverse fields such as energy, biosensors, bioimaging, and optoelectronics. They can be generated via cutting carbon precursors, such as graphene, graphene oxide and carbon fiber, into the smaller pieces by chemical oxidation, hydrothermal or solvothermal treatment under harsh conditions which requires treatment with sulfuric acid, nitric acid or other strong oxidizers (Mei et al. 2016; Lin et al. 2014). These pathways have some drawbacks such as potential safety risks, environmental pollution, higher costs, complex fabrication and post-processing procedures (Chen et al. 2018). Thus, finding environmentally and eco-friendly approaches and innovative greener precursors are crucial in this field.

\section{Eco-friendly and sustainable synthesis of graphene quantum dots}

Preparation of graphene quantum dots often needs strong acids or organic solvents, and their green production on sustainable methods still face important challenges; therefore eco-friendly synthetic approaches with easy separation and without complicated post-processes should be developed, in which the natural renewable raw materials are used as precursors. For instance, graphene quantum dots have been synthesized using cotton cellulose where the reaction system comprised cellulose and water, in the absence of any other hazardous and chemical materials. The synthetic mechanism suggested that the preparative procedure for graphene quantum dots necessitates hydrolysis followed by cyclic condensation. With highly photoluminescent properties, favorable hydrophilicity, low cytotoxicity and excellent biocompatibility, the graphene quantum dots have been successfully applied in bioimaging (Chen et al. 2019).

Graphene quantum dots $(\sim 2.25-3.50 \mathrm{~nm})$ have been generated via a facile, eco-friendly and one-pot hydrothermal reaction, with starch as a precursor; the preparative procedure entails initially the hydroxylation followed by ring-closure condensation. The produced graphene quantum dots had appropriate hydrophilicity, low cytotoxicity and highly photoluminescence emission, and were applied for cell imaging (Chen et al. 2018). Additionally, a simple and high-yielding hydrothermal approach for fabricating graphene quantum dots from glucose was reported; ensuing graphene quantum dots, with fluorescence quantum yield of $44.3 \%$, exhibited significant green photoluminescence and 
excitation-independent photoluminescence emission properties (Gu et al. 2014).

A facile one-pot solid-phase method was reported for synthesizing $N$-doped graphene quantum dots using citric acid as the carbon source and 3,4-dihydroxy-L-phenylalanine as the nitrogen source; ensuing $\mathrm{N}$-graphene quantum dots with oxygen-rich functional groups, were uniform with an average diameter of $12.5 \mathrm{~nm}$ and served as highly efficient fluorosensor for detection of $\mathrm{Hg}^{2+}$ because of the effective quenching effect of metal ions via non-radiative electron transfer. This selective fluorosensor showed high sensitivity toward $\mathrm{Hg}^{2+}$ with a detection limit of $8.6 \mathrm{nM}$ and was practically used for the effective detection of $\mathrm{Hg}^{2+}$ in riverwater samples (Shi et al. 2015a). An eco-friendly approach to prepare $\mathrm{N}$-graphene quantum dots with a high quantum yield of $28.10 \%$ has been described which showed strong blue fluorescence emission with the maximum emission and excitation at $450 \mathrm{~nm}$ and $355 \mathrm{~nm}$, respectively. Taking advantage of the effective quenching effect of $\mathrm{Hg}^{2+}$ on $\mathrm{N}$-graphene quantum dots, they were developed for the efficient and sensitive detection of $\mathrm{Hg}^{2+}$ with a relatively low detection limit of $0.032 \mu \mathrm{M}$. Based on the selective coordination of biothiols and $\mathrm{Hg}^{2+}$, the fluorescence of the $\mathrm{N}$-graphene quantum dot/Hg system was recovered with the addition of biothiols. This fluorescent "Off-On" process displayed a sensitive response to biothiols with a detection limit of $0.036 \mu \mathrm{M}$ for cysteine and $0.034 \mu \mathrm{M}$ for glutathione. The $N$-graphene quantum dot-based fluorescence method has been successfully used to monitor $\mathrm{Hg}^{2+}$ in real water samples and biothiols in serum samples (Yan et al. 2016).

Silica supported silver nanoparticles and graphene quantum dots compounds have been designed and synthesized via a greener photochemical approach and an electrophoresis deposition technique to provide a highly active surfaceenhanced Raman scattering substrate. In this method, the electrochemically prepared aqueous solution of graphene quantum dots was used both, as a solvent and a reducing agent to generate in situ silver-graphene quantum dots compounds under ultraviolet irradiation conditions. These compounds were collected on $\mathrm{SiO}_{2}$ supported $\mathrm{Si}$ substrate through the electrophoresis deposition technique. Benefiting from their proper size $(\sim 1-4 \mathrm{~nm})$ and distribution in the spatial gaps between adjacent silver nanoparticles, graphene quantum dots could act as "hot spot" sites for lighting up the Raman scattering signals. Together with the enhanced adsorption of Rhodamine 6G (R6G) molecules through $\pi-\pi$ stacking, the electrostatic interactions from graphene quantum dots, and the enlarged specific surface area provided by the $\mathrm{SiO}_{2}$ template, the as-prepared substrate showed a strong surface-enhanced Raman scattering signal with excellent reproducibility, the detection limit of R6 G being pushed to $8.0 \times 10^{-14} \mathrm{M}$ (Ge et al. 2016).

A by-product obtained from coking industries, coal tar pitch, has an exclusive molecule structure including an aromatic nucleus with various side chains bonding on this graphene-like nucleus, with a structural similarity to the structure of graphene quantum dots. An approach to convert coal tar pitch to, mono-dispersed graphene quantum dots $(\sim 1.7 \pm 0.4 \mathrm{~nm})$ by applying oxidation with hydrogen peroxide under mild conditions has been described with high yield more than $80 \mathrm{wt} \%$ (Liu et al. 2018a). These graphene quantum dots were significantly soluble and strongly fluorescent in aqueous solution (Fig. 9) (Liu et al. 2018a).

A greener and economical method has been disclosed to synthesize water-soluble graphene quantum dots from cow's milk for concurrent drug delivery and imaging in cancers. These spherical and multi-fluorescent quantum dots $(\sim 5 \mathrm{~nm})$ were prepared via one-pot microwave-assisted heating approach. It was revealed that heating time and ionic strength significantly influence on photoluminescence characteristics of them. Berberine hydrochloride was attached on graphene quantum dots (88\% efficacy in drug loading)

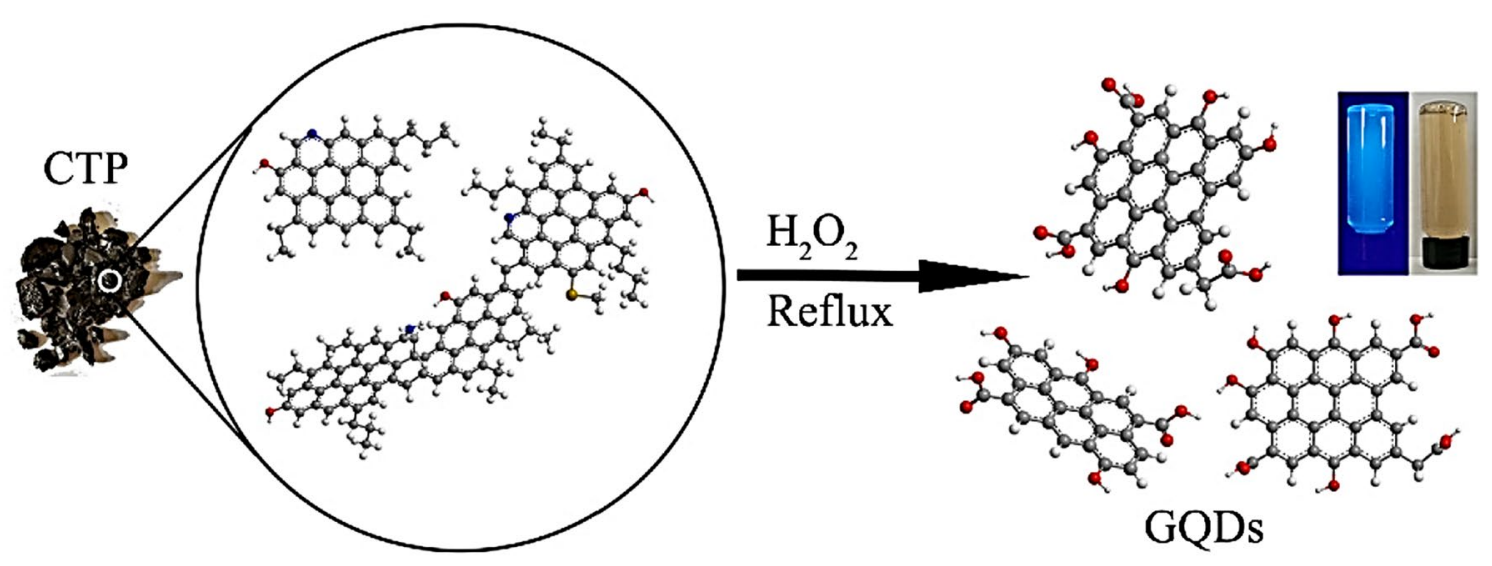

Fig. 9 Green synthesis of graphene quantum dots using coal tar pitch (CTP). Reprinted with permission from Liu et al. (2018a) 
(Thakur et al. 2016). Consequently, the graphene quantum dots were biocompatible with L929 cells, but the produced theranostic complex exhibited influential cytotoxic effects on diverse examined cancerous cell lines. Because of drug delivery and bioimaging characteristics of the prepared complex, it showed in vitro theranostic applications in cancer therapies (Thakur et al. 2016).

An approach was described involving hydrazine hydrateassisted hydrothermal cutting followed by functionalizations with polyethylenimine for producing remarkably fluorescent graphene quantum dots from coffee grounds. The polyethylenimine-functionalized graphene quantum dots presented enhanced band-edge photoluminescence with single exponential decay, and their sensing and bioimaging applications were documented (Wang et al. 2016b).

Greener synthetic method for producing fluorescent graphene quantum dots without involving any harsh reagents has been documented wherein graphene oxide was applied used as a precursor, and hydrothermal synthesis (about $2 \mathrm{~h}$ ) was accomplished with assistance from hydrogen peroxide. The prepared graphene quantum dots showed high photostability and significant biocompatibility as demonstrated by cell viability evaluations. These quantum dots can be applied as fluorescent nano-probes, because of the cell-graphene quantum dots interactions as they exhibited high potentials for bioimaging, diagnostics and drug delivery (Halder et al. 2018).

\section{Biomedical and biotechnological applications}

\section{Drug delivery and cancer therapy}

Preparation of drug delivery systems based on graphene quantum dots can find diverse applications in bio- and nanomedicine (Dong et al. 2018) and multifunctional graphene quantum dots can be harnessed for targeted cellular imaging, which is useful for cancer therapy (Wang et al. 2014b). Drug delivery systems based on arginine-glycine-aspartic acidconjugated graphene quantum dots were applied in load of doxorubicin (an antitumor drug) for targeted imaging and drug delivery. Indeed the characteristic stable fluorescence of graphene quantum dots permitted the real-time analyses of the cellular uptake from the produced nanoassembly and the following doxorubicin drug release. The doxorubicin releasement showed significant $\mathrm{pH}$ dependence and implied hydrogen-bonding interaction between graphene quantum dots and doxorubicin; the graphene quantum dots can be served as pH-sensitive drug carriers (Dong et al. 2018). Compared to free doxorubicin, the prepared conjugates revealed remarkable cytotoxicity effects to U251 glioma cells within diverse range of doxorubicin concentrations. Findings form the cellular uptake of these conjugates demonstrated that doxorubicin and some graphene quantum dots have entered into cell nuclei after incubation $(\sim 16 \mathrm{~h})$. These combinational enhancements with suitable nuclear delivery enhanced the doxorubicin cytotoxicity effects, noticeably (Dong et al. 2018). Additionally, the prepared folic acid-conjugated graphene quantum dots could be applied for loading of doxorubicin, real-time evaluating of cellular uptake and the consequent drug release. This prepared nanoassembly was precisely internalized promptly by HeLa cells through receptor-mediated endocytosis, whereas doxorubicin release and accumulations were sustained. In vitro toxicity studies revealed that the produced nanoassembly targeted $\mathrm{HeLa}$ cells differentially and efficiently while showing meaningful decrease in cytotoxicity on non-target cells (Wang et al. 2014b).

The engineered nanocarriers comprising biodegradable charged polyester vectors and graphene quantum dots were evaluated for their therapeutically influences on pancreatic cancers (MiaPaCa-2 cells) (Yang et al. 2019a). These nanocarriers were applied for co-loading doxorubicin and small interfering ribonucleic acids. Additionally, they showed significant physiological stabilities, outstanding K-ras downregulation activities, and operative bioactivity inhibitions for the examined cells. Further, laser light has been applied for generating heat for the nanocomplexes through the photothermal effects for cellular destruction; laser triggered the payloads release from the prepared nanostructured complexes and this activated release function significantly accelerated their anticancer activities of them. Moreover, the evaluation of initial colony generation showed that these complexes can be considered as promising carrier candidates for in vivo analyses (Yang et al. 2019a).

\section{Cytotoxicity, autophagy and mutagenicity}

Graphene quantum dots ( 160-280 nm) were prepared and biologically assessed by employing two mice models to assess their in vitro mutagenicity. After radiolabeling experiment, it was shown that stable radiolabeled graphene quantum dots were prepared with a high yield (>90\%). The in vivo investigation displayed an ubiquitous behavior when used for healthy animals, with a high uptake by liver $(>26 \%)$ and small intestine $(>25 \%)$. Furthermore, in inflammation/VEGF hyper-expression animal model (endometriosis), a very peculiar behavior of graphene quantum dots was detected, with a high uptake by kidneys (over 85\%) (de Menezes et al. 2019).

The cytotoxicity and autophagy induction of $\mathrm{COOH}$-graphene quantum dots, $\mathrm{OH}$-graphene quantum dots, and $\mathrm{NH}_{2}$-graphene quantum dots have been investigated (Xie et al. 2019). The $\mathrm{OH}$-graphene quantum dots were found to be the most toxic, as substantial cell death was induced at the concentration of $100 \mu \mathrm{g} \mathrm{mL}^{-1}$, as indicated by WST-1 assay as well as Annexin-V-FITC/PI apoptosis 
assessment, whereas $\mathrm{COOH}$ - and $\mathrm{OH}$-graphene quantum dots were non-cytotoxic within the analyzed concentrations. Additionally, $\mathrm{OH}-$ and $\mathrm{NH}_{2}$-graphene quantum dots stimulated autophagy of cells with different grades except for $\mathrm{COOH}$-graphene quantum dots; it was revealed that all these quantum dots meaningfully activated p-p38MAPK, and p-ERK $1 / 2$ was obstructed by $\mathrm{OH}-$ and $\mathrm{NH}_{2}$-graphene quantum dots but activated by $\mathrm{COOH}$-graphene quantum dots. Further, p-JNK was obstructed by $\mathrm{COOH}-$ and $\mathrm{NH}_{2}$ graphene quantum dots, while activated by $\mathrm{OH}$-graphene quantum dots. Concurrently, Akt was activated by $\mathrm{OH}-$ graphene quantum dots, but inhibited by $\mathrm{NH}_{2}$-graphene quantum dots. The autophagy inhibition effects from 3-MA could meaningfully improve the cytotoxicity effects of graphene quantum dots, indicating that autophagy had a protecting effects against the examined quantum dot toxicity (Xie et al. 2019).

\section{Imaging and bioimaging}

Because of the stable photoluminescence, low cytotoxicity, excellent solubility and biocompatibility, the graphene quantum dots are especially eco-friendly and were illustrated to be excellent probes for bioimaging. In one study, synthesis of strongly green-photoluminescent graphene quantum dots on large scale was reported; the produced graphene quantum dots showed significant fluorescence with photoluminescence quantum yields as high as $11.4 \%$. Additionally, the graphene quantum dots were readily soluble in water and most polar organic solvents with no further chemical modifications (Zhu et al. 2011).

Graphene quantum dots $(\sim 10 \mathrm{~nm})$ have been synthesized by vigorous oxidation of graphite. The prepared graphene quantum dots showed good physiological solubility, high photostability, low cytotoxicity, and yellow-green fluorescence with quantum yield of $\sim 7 \%$. They have been investigated for cell imaging applications (Zhang et al. 2012).

In the field of bioimaging applications of graphene quantum dots, there are still some important issues which need to be resolved. Though graphene quantum dots with emission wavelengths ranging from ultraviolet to near infrared were prepared through different strategies, the described quantum yields of graphene quantum dots were considerably lower than conventional semiconductor quantum dots; thus the quantum yields improvement of graphene quantum dots is prerequisite. Graphene quantum dots with bright red/near infrared emissions can be applied as suitable nano-probes for bioimaging (Wang et al. 2014a; Namdari et al. 2017).

The multifunctional nano-probes with great advancements can be applied for diverse fields of imaging and bioimaging; the radioactive and optical characteristics of graphene quantum dots can be useful for simultaneously imaging and therapy. Important challenges for designing graphene quantum dots-based nano-probes for optical imaging simultaneously, magnetic resonance imaging, and computed tomography evaluating should be perceived (Wang et al. 2014a; Namdari et al. 2017). Targeted tumors imaging based on graphene quantum dots has been reported in vivo, infrequently. The subsequent forms of cancer diagnostic agents applied for small animals require enhanced accumulations in tissues of tumors. The functionalization of graphene quantum dots with peptides or antibodies for imaging with high cancers targeting issues should be additionally investigated. The optimization of emission characteristics and multi-photon excitations of graphene quantum dots, their innovative neurobehavioral analyses applications, the brain gene therapy, and brain barrier penetration through blood capillaries, should be scrutinized (Dager et al. 2019; Sharma and Das 2019; Wang et al. 2014a; Namdari et al. 2017). The side effects, which possibly can be detected by applying graphene quantum dots, need to be evaluated. The gene expression and toxicity as well as cytotoxicity evaluations of graphene quantum dots with various surface coatings, morphologies and sizes should be assessed; the biodistribution analyses of graphene quantum dots in different animal models are essential (Wang and Hu 2014; Huang et al. 2019b; Zhu et al. 2011; Zhang et al. 2012; Wang et al. 2014a; Namdari et al. 2017).

Graphene quantum dots modified with polyethyleneimine or (3-carboxyl) phenyl bromide phosphine have been prepared via eco-friendly, rapid, cost-effective and large-scale preparative strategy (Fan et al. 2019). The graphene quantum dots-polyethyleneimine was generated by a simple hydrothermal procedure, and then (3-carboxyl) phenyl bromide phosphine was conjugated to the graphene quantum dotspolyethyleneimine through the amide linkage; average sizes of the prepared graphene quantum dots-polyethyleneimine and -(3-carboxyl) phenyl bromide phosphine being 3.75 and $3.25 \mathrm{~nm}$, respectively. These two composites showed significant optical property, low cytotoxicity and selective targeting and imaging characteristics for cell nucleus or mitochondria, suggesting applications, including cell nucleus imaging or mitochondria imaging in vivo and in vitro for diagnosis and therapy (Fan et al. 2019).

\section{Challenges and opportunities}

The optical and electrochemical detection of carbon and graphene quantum dots are of great interest to nanoresearchers in biomedical applications, but there are important challenging issues regarding their production (Fig. 10); some of them are highlighted in this section. Expectantly, increasing interest in the fabrication of these quantum dots, in view of their straightforward production and their integration with other nanomaterials, is sustainable. Although various 


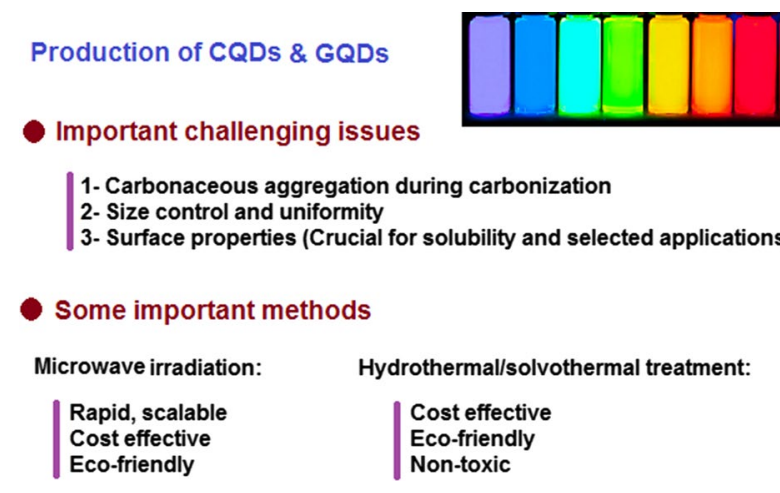

Fig. 10 Issues and related methods for production of carbon and graphene quantum dot. CQDs: Carbon quantum dots, GQDs: Graphene quantum dots

processes and starting materials have been researched for their assembly, none or handful of these nanostructures have been able to make into marketable products yet (Liu et al. 2017b; Wang et al. 2016b; Murugan et al. 2019; Halder et al. 2018; Chen et al. 2019; de Menezes et al. 2019; Barras et al. 2016; Nekoueian et al. 2019; Li et al. 2015; Mei et al. 2016; Lin et al. 2014).

One of the important challenges is to optimize the production methodologies and improve the control over the sizes and morphologies of the produced particles; standardization of the fabrication processes should be accomplished. Considerable important variations exist with significant results on the carbon-based sensors functions and their related biocompatibility. Because, the fluorescence characteristics and quantum yields are associated with the inclusive composition and the existence of remaining chemical groups on the carbon and graphene quantum dots surfaces, this standardization is significantly essential. Optimized synthetic strategies are crucial for scaling up the processes, and in this context, applying simple, greener, environmentally friendly and cost-effective techniques are very critical. Using synthetic approaches that rely on renewable starting materials is remarkably interesting and requires investigations for commercial and scale-up production. On the other hand, applying synthetic methods at lower temperatures (low-energy input) using earth-abundant starting ingredients is still an important challenge for researchers in the field. Photoluminescence is one of the extremely attractive characteristics of carbon and graphene quantum dots, but these properties are highly dependent on the raw materials deployed in fabrication and the presence of surface functionalities on these particles which are noticeable in the case of carbon quantum dots from organic molecules and biomass. Most importantly, one of the lingering challenges has been to improve and develop the quantum yield of carbon quantum dots while taking full advantage of their intrinsic characteristics and to fine-tune their emission spectrum; the improvement in carbon quantum dots with strong fluorescence emission is crucial for biomedical imaging without harmful effects (Liu et al. 2017b; Wang et al. 2016b; Murugan et al. 2019; Halder et al. 2018; Chen et al. 2019; de Menezes et al. 2019; Barras et al. 2016; Nekoueian et al. 2019; Li et al. 2015; Mei et al. 2016; Lin et al. 2014).

Toxicity issues should be systematically and comprehensively evaluated for appropriate applications in nano- and biomedicines. Determining how to engineer well-defined and optimized particles with high yields is still an important challenge; the electrical conductivity of carbon quantum dots nevertheless remains incompetently researched. Although their suitable water dispersibility renders these nanomaterials well-adapted for bio- and nano-medical applications, but their solubility precludes using classical electrode alteration processes such as drop casting and spraying. Carbon and graphene quantum dots can be applied as outstanding alternatives for biosensors and bioimaging applications especially carbon quantum dots being generally non-toxic show great photoluminescent characteristics (Nekoueian et al. 2019; Shen et al. 2012).

Carbon dots show low toxicity, good biocompatibility, and significant water solubility, and they have promising applications in sensing and imaging. The future applications of carbon dots in bioimaging and biosensing should include the improvement of selectivity, sensitivity, and stability of these systems; interference reduction from background and autofluorescence from biological experiments should be covered. Innovative fluorescent characteristics and the means of controlling these properties are hurdles for regulating the luminescent mechanism and the construction approach. The synthesis tactic, crystalline structure, non-quantitative surface structure, nano-size effect, and virtual size polydispersion are closely related to the luminescence mechanism, which can be resolved by careful evaluation, precise synthesis, and intelligent analysis. Future investigations should focus on the enhancement of quantum yield, biocompatibility, and synthesis approaches that should encompass green, eco-friendly, low-energy, low-cost, simple, and efficient routes, suitable nano-size, and compositional and structural alterations (Huang et al. 2019b; Iravani and Varma 2020).

Overall, the appraisal of these studies show that researchers are focusing on identifying innovative sources and methods based on green chemistry principals for synthesizing carbon and graphene quantum dots which have significant potentials for biomedical applications, including cell labeling, diagnostics or controlled drug delivery and release systems. Simple strategies providing feasible methods toward the commercial high yield production of carbon and graphene quantum dots are needed using cheap material sources, greener reagents under mild conditions. Although various approaches have been suggested for producing carbon and graphene quantum dots, well-defined structure and 
precise sizes are barely available yet (D'souza et al. 2018; Kasibabu et al. 2015). It is vital to prepare quantum dots in a facile and greener manner with designed structure and size for proper investigations and biomedical applications. The synthetic routes and sources of carbon are important factors, which influence the sizes, morphologies and characteristics of the final product; the sizes for carbon dots are very crucial for understanding quantum phenomena, and also for biomedical applications and optoelectronics (Li et al. 2019).

Recently, various pathways have been outlined for the fabrication of both pure or doped carbon and graphene quantum dots with varied morphologies and characteristics. Though, discrete sustainable and greener synthetic approaches have been applied for synthesizing carbon quantum dots, investigations into graphene quantum dots are still at a growing stage, and more elaborate and critical studies are needed. As an example, the well-defined and atom-precise structures have not been reported comprehensively, thus restricting the profound evaluation of the relationships between structures and characteristics, detailed properties regulations, and comprehensive assessments of innovative synthetic approaches and applications. An all-inclusive consideration toward the optical characteristics of carbon dots is needed; additional theoretical evaluations and better understanding the mechanistic aspects are very critical.

\section{Conclusion}

Advancements in nanosciences for advanced and developed diagnosis and personalized therapy of various complex diseases (especially, cancers) are of contemporary interest. Particularly, semiconductor quantum dots have been developed as innovative platforms for high-throughput quantitative analyses of multiple biomarkers in cells and clinical tissue samples (ex vivo), in vivo evaluations of cells with diseases, and potentially targeted and traceable drug delivery. Indeed, quantum dots show significant potentials in such biomedical, bioimaging, and photoluminescent applications, and they can be harnessed as promising fluorescent probes for imaging with low cytotoxicity as they show remarkable potentials in bioanalysis and related fields. Carbon quantum dots have received widespread attentions owing to their suitable biocompatibility, robust chemical inertness and higher resistance to photobleaching. Additionally, their optical characteristics can be adjusted via size control, chemical doping and functionalization for featured and specific applications.

Biomass-based carbon quantum dots have become substantial carbon materials because of their cost-effectiveness, ease of fabrication and lower environmental impact. But, it appears that there are not many investigations regarding using organisms (especially, cyanobacteria) as carbon sources for production of fluorescent carbon quantum dots.
Additionally, graphene quantum dots are attractive fluorophores because of their outstanding photoluminescence characteristics, water solubility, low cost, and toxicity. For instance, in some cases, $\mathrm{COOH}$-graphene quantum dots demonstrated significant biocompatibility, and may be considered for biological and medical applications. It appears that considerable efforts should be expanded to find greener, simple, efficient, and eco-friendly fabrication methodologies for carbon and graphene quantum dots as well as their effective use in bio- and nano-medical applications. More scientific investigations need to be undertaken for scaling up and the commercial production of quantum dots by applying simple, efficient, economic and sustainable strategies with focus on biocompatibility and low cytotoxicity.

Acknowledgements RSV was supported, in part, from ERDF project "Development of pre-applied research in nanotechnology and biotechnology" (No. CZ.02.1.01/0.0/0.0/17_048/0007323).

\section{Compliance with ethical standards}

Conflict of interest Authors declare no conflict of interest.

\section{References}

Amin N, Afkhami A, Hosseinzadeh L, Madrakian T (2018) Green and cost-effective synthesis of carbon dots from date kernel and their application as a novel switchable fluorescence probe for sensitive assay of Zoledronic acid drug in human serum and cellular imaging. Anal Chim Acta 1030:183-193. https://doi.org/10.1016/j. aca.2018.05.014

Arkan E, Barati A, Rahmanpanah M, Hosseinzadeh L, Moradi S, Hajialyani M (2018) Green synthesis of carbon dots derived from walnut oil and an investigation of their cytotoxic and apoptogenic activities toward cancer cells. Adv Pharm Bull 8:149-155. https ://doi.org/10.15171/apb.2018.018

Atchudan R, Edison TNJI, Lee YR (2016a) Nitrogen-doped carbon dots originating from unripe peach for fluorescent bioimaging and electrocatalytic oxygen reduction reaction. J Colloid Interface Sci 482:8-18. https://doi.org/10.1016/j.jcis.2016.07.058

Atchudan R, Edison TNJI, Sethuraman MG, Lee YR (2016b) Efficient synthesis of highly fluorescent nitrogen-doped carbon dots for cell imaging using unripe fruit extract of Prunus mume. Appl Surf Sci 384:432-441. https://doi.org/10.1016/j.apsus c. 2016.05 .054

Atchudan R, Edison TNJI, Chakradhar D, Perumal S, Shim J-J, Lee YR (2017) Facile green synthesis of nitrogen-doped carbon dots using Chionanthus retusus fruit extract and investigation of their suitability for metal ion sensing and biological applications. Sens Actuators B Chem 246:497-509. https://doi.org/10.1016/j. snb.2017.02.119

Baker SN, Baker GA (2010) Luminescent carbon nanodots: emergent nanolights. Angew Chem Int Ed 49(38):6726-6744. https://doi. org/10.1002/anie.200906623

Balajia M, Jegatheeswarana S, Nithyaa P, Boomib P, Selvamc S, Sundrarajana M (2018) Photoluminescent reduced graphene oxide quantum dots from latex of Calotropis gigantea for metal sensing, radical scavenging, cytotoxicity, and bioimaging in Artemia 
salina: a greener route. J Photochem Photobiol 178:371-379. https://doi.org/10.1016/j.jphotobiol.2017.11.031

Bandi R, Reddy Gangapuram BR, Dadigala R, Eslavath R, Singh SS, Guttena V (2016) Facile and green synthesis of fluorescent carbon dots from onion waste and their potential applications as sensor and multicolour imaging agents. RSC Adv 6:28633-28639. https://doi.org/10.1039/C6RA01669C

Bano D, Kumar V, Singha VK, Hasan SH (2018) Green synthesis of fluorescent carbon quantum dots for the detection of mercury(II) and glutathione. New J Chem 42:5814-5821. https://doi. org/10.1039/C8NJ00432C

Barras A, Pagneux Q, Sane F, Wang Q, Boukherroub R, Hober D, Szunerits S (2016) High efficiency of functional carbon nanodots as entry inhibitors of herpes simplex virus type 1. ACS Appl Mater Interfaces 8:9004-9013. https://doi.org/10.1021/acsam i.6b01681

Bourlinos AB, Stassinopoulos A, Anglos D, Zboril R, Georgakilas V, Giannelis EP (2008) Photoluminescent carbogenic dots. Chem Mater 20(14):4539-4541. https://doi.org/10.1021/cm800506r

Campuzano S, Yáñez-Sedeño P, Pingarrón JM (2019) Carbon dots and graphene quantum dots in electrochemical biosensing. Nanomaterials (Basel) 9:634. https://doi.org/10.3390/nano9040634

Cao L, Wang X, Meziani MJ, Lu F, Wang H, Luo PG, Lin Y, Harruff BA, Veca LM, Murray D (2007) Carbon dots for multiphoton bioimaging. J Am Chem Soc 129(37):11318-11319. https://doi. org/10.1021/ja0735271

Chen W, Li D, Tian L, Xiang W, Wang T, Hu W, Hu Y, Chen S, Chen J, Dai Z (2018) Synthesis of graphene quantum dots from natural polymer starch for cell imaging. Green Chem 20:4438-4442. https://doi.org/10.1039/C8GC02106F

Chen W, Shen J, Lv G, Li D, Hu Y, Zhou C, Liu X, Dai Z (2019) Green synthesis of graphene quantum dots from cotton cellulose. Chem Sel 4:2898-2902. https://doi.org/10.1002/slct.201803512

Cheng C, Shi Y, Li M, Xing M, Wu Q (2017) Carbon quantum dots from carbonized walnut shells: structural evolution, fluorescence characteristics, and intracellular bioimaging. Mater Sci Eng, C 79:473-480. https://doi.org/10.1016/j.msec.2017.05.094

D'souza SL, Chettiar SS, Koduru JR, Kailasaa SK (2018) Synthesis of fluorescent carbon dots using Daucus carota subsp. sativus roots for mitomycin drug delivery. Optik 158:893-900. https:// doi.org/10.1016/j.ijleo.2017.12.200

Dager A, Uchida T, Maekawa T, Tachibana M (2019) Synthesis and characterization of mono-disperse carbon quantum dots from fennel seeds: photoluminescence analysis using machine learning. Sci Rep 9:14004. https://doi.org/10.1038/s41598-019-50397-5

Dai H, Yang C, Tong Y, Xu G, Ma X, Lin Y, Chen G (2012) Labelfree electrochemiluminescent immunosensor for $\alpha$-fetoprotein: performance of Nafion-carbon nanodots nanocomposite films as antibody carriers. Chem Commun 48(25):3055-3057. https ://doi.org/10.1039/C1CC16571B

Das R, Bandyopadhyay R, Pramanik P (2018) Carbon quantum dots from natural resource: a review. Mater Today Chem 8:96-109. https://doi.org/10.1016/j.mtchem.2018.03.003

de Menezes FD, Dos Reis SRR, Pinto SR, Portilho FL, do Vale Chaves E, Mello F, Helal-Neto E, da Silva de Barros AO, Alencar LMR, de Menezes AS, Dos Santos CC, Saraiva-Souza A, Perini JA, Machado DE, Felzenswalb I, Araujo-Lima CF, Sukhanova A, Nabiev I, Santos-Oliveira R (2019) Graphene quantum dots unraveling: green synthesis, characterization, radiolabeling with $99 \mathrm{mTc}$, in vivo behavior and mutagenicity. Mater Sci Eng C Mater Biol Appl 102:405-414. https://doi.org/10.1016/j. msec.2019.04.058

de Yro PAN, Quaichon GMO, Cruz RAT, Emolaga CS, Que MCO, Magdaluyo Jr ER, Basilia BA (2019) Hydrothermal synthesis of carbon quantum dots from biowaste for bio-imaging. In: AIP conference proceedings, vol 2083. https://doi.org/10.1063/1.5094310
Ding Z, Li F, Wen J, Wang X, Sun R (2018) Gram-scale synthesis of single-crystalline graphene quantum dots derived from lignin biomass. Green Chem 20:1383-1390. https://doi.org/10.1039/ C7GC03218H

Dong Y, Zhou N, Lin X, Lin J, Chi Y, Chen G (2010) Extraction of electrochemiluminescent oxidized carbon quantum dots from activated carbon. Chem Mater 22(21):5895-5899. https://doi. org/10.1021/cm1018844

Dong Y, Pang H, Yang HB, Guo C, Shao J, Chi Y, Li CM, Yu T (2013) Carbon-based dots co-doped with nitrogen and sulfur for high quantum yield and excitation-independent emission. Angew Chem Int Ed 52(30):7800-7804. https://doi.org/10.1002/ anie. 201301114

Dong J, Wang K, Sun L, Sun B, Yang M, Chen H, Wang Y, Sun J, Dong L (2018) Application of graphene quantum dots for simultaneous fluorescence imaging and tumor-targeted drug delivery. Sens Actuators B Chem 256:616-623. https://doi.org/10.1016/j. snb.2017.09.200

Edison TN, Atchudan R, Sethuraman MG, Shim JJ, Lee YR (2016a) Microwave assisted green synthesis of fluorescent N-doped carbon dots: cytotoxicity and bio-imaging applications. J Photochem Photobiol, B 161:154-161. https://doi.org/10.1016/j.jphotobiol .2016 .05 .017

Edison TN, Atchudan R, Shim JJ, Kalimuthu S, Ahn BC, Lee YR (2016b) Turn-off fluorescence sensor for the detection of ferric ion in water using green synthesized $\mathrm{N}$-doped carbon dots and its bio-imaging. J Photochem Photobiol, B 158:235-242. https ://doi.org/10.1016/j.jphotobiol.2016.03.010

Fan Z, Nie Y, Wei Y, Zhao J, Liao X, Zhang J (2019) Facile and largescale synthesis of graphene quantum dots for selective targeting and imaging of cell nucleus and mitochondria. Mater Sci Eng, C 103:109824. https://doi.org/10.1016/j.msec.2019.109824

Fang L, Zhang L, Chen Z, Zhu C, Liu J, Zheng J (2017) Ammonium citrate derived carbon quantum dot as on-off-on fluorescent sensor for detection of chromium (VI) and sulfites. Mater Lett 191:1-4. https://doi.org/10.1016/j.matlet.2016.12.098

Feng X, Jiang Y, Zhao J, Miao M, Cao S, Fang J, Shi L (2015a) Easy synthesis of photoluminescent $\mathrm{N}$-doped carbon dots from winter melon for bio-imaging. RSC Adv 5:31250-31254. https://doi. org/10.1039/C5RA02271A

Feng Y, Zhong D, Miao H, Yang X (2015b) Carbon dots derived from rose flowers for tetracycline sensing. Talanta 140:128-133. https ://doi.org/10.1016/j.talanta.2015.03.038

Feng J, Wang W-J, Hai X, Yu Y-L, Wang J-H (2016) Green preparation of nitrogen-doped carbon dots derived from silkworm chrysalis for cell imaging. J Mater Chem B 4(3):387-393. https://doi. org/10.1039/C5TB01999K

Ge J, Li Y, Wang J, Pu Y, Xue W, Liu X (2016) Green synthesis of graphene quantum dots and silver nanoparticles compounds with excellent surface enhanced Raman scattering performance. J Alloys Compd 663:166-171. https://doi.org/10.1016/j.jallc om.2015.12.055

Gogoi N, Chowdhury D (2014) Novel carbon dot coated alginate beads with superior stability, swelling and $\mathrm{pH}$ responsive drug delivery. J Mater Chem B 2(26):4089-4099. https://doi.org/10.1039/ C3TB21835J

Gogoi N, Barooah M, Majumdar G, Chowdhury D (2015) Carbon dots rooted agarose hydrogel hybrid platform for optical detection and separation of heavy metal ions. ACS Appl Mater Interfaces 7(5):3058-3067. https://doi.org/10.1021/am506558d

Gonçalves H, Jorge PA, Fernandes J, da Silva JCE (2010) Hg (II) sensing based on functionalized carbon dots obtained by direct laser ablation. Sens Actuators B Chem 145(2):702-707. https://doi. org/10.1016/j.snb.2010.01.031

Gu J, Hu MJ, Guo QQ, Ding ZF, Sun XL, Yang J (2014) Highyield synthesis of graphene quantum dots with strong green 
photoluminescence. RSC Adv 4:50141-50144. https://doi. org/10.1039/C4RA10011E

Gu D, Shang S, Yu Q, Shen J (2016) Green synthesis of nitrogendoped carbon dots from lotus root for $\mathrm{Hg}$ (II) ions detection and cell imaging. Appl Surf Sci 390:38-42. https://doi. org/10.1016/j.apsusc.2016.08.012

Habiba K, Bracho-Rincon DP, Gonzalez-Feliciano JA, VillalobosSantos JC, Makarov VI, Ortiz D, Avalos JA, Gonzalez CI, Weiner BR, Morell G (2015) Synergistic antibacterial activity of PEGylated silver-graphene quantum dots nanocomposites. Appl Mater Today 1:80-87. https://doi.org/10.1016/j. apmt.2015.10.001

Halder A, Godoy-Gallardo M, Ashley J, Feng X, Zhou T, HostaRigau L, Sun Y (2018) One-pot green synthesis of biocompatible graphene quantum dots and their cell uptake studies. ACS Appl Bio Mater 1:452-461. https://doi.org/10.1021/acsab $\mathrm{m} .8 \mathrm{~b} 00170$

Hamilton IP, Li B, Yan X, Li L-s (2011) Alignment of colloidal graphene quantum dots on polar surfaces. Nano Lett 11(4):15241529. https://doi.org/10.1021/nl200298c

Hoan BT, Tam PD, Pham V-H (2019) Green synthesis of highly luminescent carbon quantum dots from lemon juice. J Nanotechnol 2019:2852816. https://doi.org/10.1155/2019/2852816

Hou J, Dong J, Zhu H, Teng X, Ai S, Mang M (2015a) A simple and sensitive fluorescent sensor for methyl parathion based on L-tyrosine methyl ester functionalized carbon dots. Biosens Bioelectron 68:20-26. https://doi.org/10.1016/j.bios.2014.12.037

Hou Y, Lu Q, Deng J, Li H, Zhang Y (2015b) One-pot electrochemical synthesis of functionalized fluorescent carbon dots and their selective sensing for mercury ion. Anal Chim Acta 866:69-74. https://doi.org/10.1016/j.aca.2015.01.039

HU S-L, BAI P-K, CAO S-R, SUN J (2009a) Preparation of fluorescent carbon nanoparticles by pulsed laser. Chem J Chin Univ 8:1497-1500

Hu S-L, Niu K-Y, Sun J, Yang J, Zhao N-Q, Du X-W (2009b) One-step synthesis of fluorescent carbon nanoparticles by laser irradiation. J Mater Chem 19(4):484-488. https://doi.org/10.1039/B812943F

Hu Y, Zhang L, Li X, Liu R, Lin L, Zhao S (2017) Green preparation of $\mathrm{S}$ and $\mathrm{N} \mathrm{Co-doped} \mathrm{carbon} \mathrm{dots} \mathrm{from} \mathrm{water} \mathrm{chestnut} \mathrm{and} \mathrm{onion}$ as well as their use as an off-on fluorescent probe for the quantification and imaging of coenzyme A. ACS Sustain Chem Eng 5:4992-5000. https://doi.org/10.1021/acssuschemeng.7b00393

Huang H, Lv J-J, Zhou D-L, Bao N, Xu Y, Wang A-J, Feng J-J (2013) One-pot green synthesis of nitrogen-doped carbon nanoparticles as fluorescent probes for mercury ions. RSC Adv 3:2169121696. https://doi.org/10.1039/C3RA43452D

Huang G, Chen X, Wang C, Zheng H, Huang Z, Chen D, Xie H (2017) Photoluminescent carbon dots derived from sugarcane molasses: synthesis, properties, and applications. RSC Adv 7:47840 47847. https://doi.org/10.1039/C7RA09002A

Huang C, Dong H, Su Y, Wu Y, Narron R, Yong Q (2019a) Synthesis of carbon quantum dot nanoparticles derived from byproducts in bio-refinery process for cell imaging and in vivo bioimaging. Nanomaterials (Basel) 9:387. https://doi.org/10.3390/nano9 030387

Huang S, Li W, Han P, Zhou X, Cheng J, Wena H, Xue W (2019b) Carbon quantum dots: synthesis, properties, and sensing applications as a potential clinical analytical method. Anal Methods 11:2240-2258. https://doi.org/10.1039/C9AY00068B

Iravani S (2011) Green synthesis of metal nanoparticles using plants. Green Chem 13:2638-2650. https://doi.org/10.1039/C1GC1 5386B

Iravani S, Varma R (2019a) Plant-derived edible nanoparticles and miRNAs: emerging frontier for therapeutics and targeted drugdelivery. ACS Sustain Chem Eng 7:8055-8069. https://doi. org/10.1021/acssuschemeng.9b00954
Iravani S, Varma RS (2019b) Biofactories: engineered nanoparticles via genetically engineered organisms. Green Chem 21:45834603. https://doi.org/10.1039/C9GC01759C

Iravani S, Varma RS (2020) Greener synthesis of lignin nanoparticles and their applications. Green Chem 22:612-636. https://doi. org/10.1039/C9GC02835H

Jaiswal A, Ghosh SS, Chattopadhyay A (2012) One step synthesis of C-dots by microwave mediated caramelization of poly (ethylene glycol). Chem Commun 48(3):407-409. https://doi.org/10.1039/ C1CC15988G

Janus Ł, Piątkowski M, Radwan-Pragłowska J, Bogdał D, Matysek D (2019) Chitosan-based carbon quantum dots for biomedical applications: synthesis and characterization. Nanomaterials (Basel) 9:274. https://doi.org/10.3390/nano9020274

Jiang H, Chen F, Lagally MG, Denes FS (2009) New strategy for synthesis and functionalization of carbon nanoparticles. Langmuir 26(3):1991-1995. https://doi.org/10.1021/la9022163

Jiang C, Wu H, Song X, Ma X, Wang J, Tan M (2014) Presence of photoluminescent carbon dots in Nescafe ${ }^{\circledR}$ original instant coffee: applications to bioimaging. Talanta 127:68-74. https://doi. org/10.1016/j.talanta.2014.01.046

Jiao J, Liu C, Li X, Liu J, Di D, Zhang Y, Zhao Q, Wang S (2016) Fluorescent carbon dot modified mesoporous silica nanocarriers for redox-responsive controlled drug delivery and bioimaging. J Colloid Interface Sci 483:343-352. https://doi.org/10.1016/j. jcis.2016.08.033

Joseph J, Anappara AA (2017) White-light-emitting carbon dots prepared by the electrochemical exfoliation of graphite. ChemPhysChem 18(3):292-298. https://doi.org/10.1002/cphc.201601020

Karthik S, Saha B, Ghosh SK, Singh NP (2013) Photoresponsive quinoline tethered fluorescent carbon dots for regulated anticancer drug delivery. Chem Commun 49(89):10471-10473. https://doi. org/10.1039/C3CC46078A

Kasibabu BSB, D'souza SL, Jha S, Kailasa SK (2015) Imaging of bacterial and fungal cells using fluorescent carbon dots prepared from carica papaya juice. J Fluoresc 25:803-810. https://doi. org/10.1007/s10895-015-1595-0

Keerthana AK, Ashraf PM (2019) Carbon nanodots synthesized from chitosan and its application as a corrosion inhibitor in boat-building carbon steel BIS2062. Appl Nanosci. https://doi.org/10.1007/ s13204-019-01177-0

Kumar A, Chowdhuri AR, Laha D, Mahto TK, Karmakar P, Sahu SK (2017) Green synthesis of carbon dots from Ocimum sanctum for effective fluorescent sensing of $\mathrm{Pb}^{2+}$ ions and live cell imaging. Sens Actuators B Chem 242:679-686. https://doi.org/10.1016/j. snb.2016.11.109

Kumawat MK, Thakur M, Gurung RB, Srivastava R (2017a) Graphene quantum dots for cell proliferation, nucleus imaging, and photoluminescent sensing applications. Sci Rep 7:1-16. https://doi. org/10.1038/s41598-017-16025-w

Kumawat MK, Thakur M, Gurung RB, Srivastava R (2017b) Graphene quantum dots from mangifera indica: application in near-infrared bioimaging and intracellular nanothermometry. ACS Sustain Chem Eng 5:1382-1391. https://doi.org/10.1021/acssuschem eng.6b01893

Lan M, Di Y, Zhu X, Ng T-W, Xia J, Liu W, Meng X, Wang P, Lee C-S, Zhang W (2015) A carbon dot-based fluorescence turn-on sensor for hydrogen peroxide with a photo-induced electron transfer mechanism. Chem Commun 51(85):15574-15577. https://doi. org/10.1039/C5CC05835J

Lee HU, Park SY, Park ES, Son B, Lee SC, Lee JW, Lee Y-C, Kang KS, Kim MI, Park HG (2014) Photoluminescent carbon nanotags from harmful cyanobacteria for drug delivery and imaging in cancer cells. Sci Rep. https://doi.org/10.1038/srep04665

Li H, He X, Kang Z, Huang H, Liu Y, Liu J, Lian S, Tsang CHA, Yang X, Lee ST (2010a) Water-soluble fluorescent carbon 
quantum dots and photocatalyst design. Angew Chem Int Ed 49(26):4430-4434. https://doi.org/10.1002/anie.200906154

Li X, Wang H, Shimizu Y, Pyatenko A, Kawaguchi K, Koshizaki N (2010b) Preparation of carbon quantum dots with tunable photoluminescence by rapid laser passivation in ordinary organic solvents. Chem Commun 47(3):932-934. https://doi. org/10.1039/C0CC03552A

Li H, He X, Liu Y, Yu H, Kang Z, Lee S-T (2011) Synthesis of fluorescent carbon nanoparticles directly from active carbon via a one-step ultrasonic treatment. Mater Res Bull 46(1):147-151. https://doi.org/10.1016/j.materresbull.2010.10.013

Li S, Wang L, Chusuei CC, Suarez VM, Blackwelder PL, Micic M, Orbulesu J, Leblanc RM (2015) Nontoxic carbon dots potently inhibit human insulin fibrillation. Chem Mater 27:1764-1771. https://doi.org/10.1021/cm504572b

Li H, Shao F-Q, Huang H, Feng J-J, Wang A-J (2016) Eco-friendly and rapid microwave synthesis of green fluorescent graphitic carbon nitride quantum dots for vitro bioimaging. Sens Actuators B Chem 226:506-511. https://doi.org/10.1016/j. snb.2015.12.018

Li M, Chen T, Gooding JJ, Liu J (2019) Review of carbon and graphene quantum dots for sensing. ACS Sens 4:1732-1748. https ://doi.org/10.1021/acssensors.9b00514

Lim SY, Shen W, Gao Z (2015) Carbon quantum dots and their applications. Chem Soc Rev 44:362-381. https://doi.org/10.1039/ C4CS00269E

Lin LX, Zhang SW (2012) Creating high yield water soluble luminescent graphene quantum dots via exfoliating and disintegrating carbon nanotubes and graphite flakes. Chem Commun 48:10177-10179. https://doi.org/10.1039/C2CC35559K

Lin Z, Xue W, Chen H, Lin J-M (2011) Peroxynitrous-acid-induced chemiluminescence of fluorescent carbon dots for nitrite sensing. Anal Chem 83(21):8245-8251. https://doi.org/10.1021/ ac202039h

Lin L, Rong M, Luo F, Chen D, Wang Y, Chen X (2014) Luminescent graphene quantum dots as new fluorescent materials for environmental and biological applications. Trends Anal Chem 54:83-102. https://doi.org/10.1016/j.trac.2013.11.001

Lin F, Bao Y-W, Wu F-G (2019) Carbon dots for sensing and killing microorganisms. C J Carbon Res 5:33. https://doi.org/10.3390/ c5020033

Liu H, Ye T, Mao C (2007) Fluorescent carbon nanoparticles derived from candle soot. Angew Chem Int Ed 46(34):6473-6475. https://doi.org/10.1002/anie.200701271

Liu R, Wu D, Liu S, Koynov K, Knoll W, Li Q (2009) An aqueous route to multicolor photoluminescent carbon dots using silica spheres as carriers. Angew Chem 121(25):4668-4671. https:// doi.org/10.1002/anie.200900652

Liu R, Wu D, Feng X, Müllen K (2011) Bottom-up fabrication of photoluminescent graphene quantum dots with uniform morphology. J Am Chem Soc 133(39):15221-15223. https://doi. org/10.1021/ja204953k

Liu C, Zhang P, Zhai X, Tian F, Li W, Yang J, Liu Y, Wang H, Wang W, Liu W (2012) Nano-carrier for gene delivery and bioimaging based on carbon dots with PEI-passivation enhanced fluorescence. Biomaterials 33(13):3604-3613. https://doi. org/10.1016/j.biomaterials.2012.01.052

Liu J, Liu Y, Liu N, Han Y, Zhang X, Huang H, Lifshitz Y, Lee S-T, Zhong J, Kang Z (2015a) Metal-free efficient photocatalyst for stable visible water splitting via a two-electron pathway. Science 347:970-974. https://doi.org/10.1126/science.aaa3145

Liu S, Zhao N, Cheng Z, Liu H (2015b) Amino-functionalized green fluorescent carbon dots as surface energy transfer biosensors for hyaluronidase. Nanoscale 7(15):6836-6842. https://doi. org/10.1039/C5NR00070J
Liu W, Li C, Ren Y, Sun X, Pan W, Li Y, Wang J, Wang W (2016) Carbon dots: surface engineering and applications. J Mater Chem B 4:5772-5788. https://doi.org/10.1039/C6TB00976J

Liu F, Zhang W, Chen W, Wang J, Yang Q, Zhu W, Wang J (2017a) One-pot synthesis of $\mathrm{NiFe}_{2} \mathrm{O}_{4}$ integrated with EDTA-derived carbon dots for enhanced removal of tetracycline. Chem Eng $\mathbf{J}$ 310:187-196. https://doi.org/10.1016/j.cej.2016.10.116

Liu ML, Lin Y, Li RS, Chen BB, Liu H, Huang CZ (2017b) Large-scale simultaneous synthesis of highly photoluminescent green amorphous carbon nanodots and yellow crystalline graphene quantum dots at room temperature. Green Chem 19:3611-3617. https:// doi.org/10.1039/C7GC01236E

Liu Q, Zhang J, He H, Huang G, Xing B, Jia J, Zhang C (2018a) Green preparation of high yield fluorescent graphene quantum dots from coal-tar-pitch by mild oxidation. Nanomaterials (Basel) 8:844. https://doi.org/10.3390/nano8100844

Liu X, Hao J, Liu J, Tao H (2018b) Green synthesis of carbon quantum dots from lignite coal and the application in $\mathrm{Fe}^{3+}$ detection. In: IOP Conference Series: Earth Environmental Science vol 113, p 012063. https://doi.org/10.1088/1755-1315/113/1/012063

Lu J, Yeo PSE, Gan CK, Wu P, Loh KP (2011) Transforming C60 molecules into graphene quantum dots. Nat Nanotechnol 6(4):247252. https://doi.org/10.1038/nnano.2011.30

Lu Y-C, Chen J, Wang A-J, Bao N, Feng J-J, Wang W, Shao L (2015) Facile synthesis of oxygen and sulfur co-doped graphitic carbon nitride fluorescent quantum dots and their application for mercury(ii) detection and bioimaging. J Mater Chem C 3:73-78. https://doi.org/10.1039/C4TC02111H

Majumdar S, Krishnatreya G, Gogoi N, Thakur D, Chowdhury D (2016) Carbon-dot-coated alginate beads as a smart stimuliresponsive drug delivery system. ACS Appl Mater Interfaces 8(50):34179-34184. https://doi.org/10.1021/acsami.6b10914

Mehta VN, Jha S, Kailasa SK (2014) One-pot green synthesis of carbon dots by using Saccharum officinarum juice for fluorescent imaging of bacteria (Escherichia coli) and yeast (Saccharomyces cerevisiae) cells. Mater Sci Eng, C 38:20-27. https://doi. org/10.1016/j.msec.2014.01.038

Mehta VN, Jha S, Basu H, Singhal RK, Kailasa SK (2015) One-step hydrothermal approach to fabricate carbon dots from apple juice for imaging of mycobacterium and fungal cells. Sens Actuators B Chem 213:434-443. https://doi.org/10.1016/j.snb.2015.02.104

Mei Q, Chen J, Zhao J, Yang L, Liu B, Liu RY, Zhang ZP (2016) Atomic oxygen tailored graphene oxide nanosheets emissions for multicolor cellular imaging. ACS Appl Mater Interfaces 8:7390-7395. https://doi.org/10.1021/acsami.6b00791

Mewada A, Pandey S, Shinde S, Mishra N, Oza G, Thakur M, Sharon M, Sharon M (2013) Green synthesis of biocompatible carbon dots using aqueous extract of Trapa bispinosa peel. Mater Sci Eng, C 33(5):2914-2917. https://doi.org/10.1016/j. msec.2013.03.018

Miao P, Han K, Tang Y, Wang B, Lin T, Cheng W (2015) Recent advances in carbon nanodots: synthesis, properties and biomedical applications. Nanoscale 7(5):1586-1595. https://doi. org/10.1039/C4NR05712K

Ming H, Ma Z, Liu Y, Pan K, Yu H, Wang F, Kang Z (2012) Large scale electrochemical synthesis of high quality carbon nanodots and their photocatalytic property. Dalton Trans 41(31):95269531. https://doi.org/10.1039/C2DT30985H

Mohammadinejad R, Karimi S, Iravani S, Varma RS (2016) Plantderived nanostructures: types and applications. Green Chem 18:20-52. https://doi.org/10.1039/C5GC01403D

Mohammadinejad R, Shavandi A, Raie DS, Sangeetha J, Soleimani M, Hajibehzad SS, Thangadurai D, Hospet R, Popoola JO, Arzani A, Gómez-Lim MA, Iravani S, Varma RS (2019) Plant molecular farming: production of metallic nanoparticles and therapeutic 
proteins using green factories. Green Chem 21:1845-1865. https ://doi.org/10.1039/C9GC00335E

Mueller ML, Yan X, Dragnea B, Li L-s (2010) Slow hot-carrier relaxation in colloidal graphene quantum dots. Nano Lett 11(1):56-60. https://doi.org/10.1021/nl102712x

Murugan N, Prakash M, Jayakumar M, Sundaramurthy A, Sundramoorthy AK (2019) Green synthesis of fluorescent carbon quantum dots from Eleusine coracana and their application as a fluorescence 'turn-off' sensor probe for selective detection of $\mathrm{Cu}^{2+}$. Appl Surf Sci 476:468-480. https://doi.org/10.1016/j. apsusc.2019.01.090

Namdari P, Negahdari B, Eatemadi A (2017) Synthesis, properties and biomedical applications of carbon-based quantum dots: an updated review. Biomed Pharmacother 87:209-222. https://doi. org/10.1016/j.biopha.2016.12.108

Nekoueian K, Amiri M, Sillanpaa M, Marken F, Boukherroub R, Szunerits S (2019) Carbon-based quantum particles: an electroanalytical and biomedical perspective. Chem Soc Rev 48:42814316. https://doi.org/10.1039/C8CS00445E

Nie H, Li MJ, Li QS, Liang SJ, Tan YY, Sheng L, Shi W, Zhang SX-A (2014) Carbon dots with continuously tunable full-color emission and their application in ratiometric $\mathrm{pH}$ sensing. Chem Mater 26:3104-3112. https://doi.org/10.1021/cm5003669

Park SY, Lee HU, Park ES, Lee SC, Lee J-W, Jeong SW, Kim CH, Lee Y-C, Huh YS, Lee J (2014) Photoluminescent green carbon nanodots from food-waste-derived sources: large-scale synthesis, properties, and biomedical applications. ACS Appl Mater Interfaces 6(5):3365-3370. https://doi.org/10.1021/am500159p

Pooja D, Saini S, Thakur A, Kumar B, Tyagi S, Nayak MK (2017) A "Turn-On" thiol functionalized fluorescent carbon quantum dot based chemosensory system for arsenite detection. J Hazard Mater 328:117-126. https://doi.org/10.1016/j.jhazm at.2017.01.015

Prasannan A, Imae T (2013) One-pot synthesis of fluorescent carbon dots from orange waste peels. Ind Eng Chem Res 52:1567315678. https://doi.org/10.1021/ie402421s

Priyadarshini E, Rawat K, Prasad T, Bohidar HB (2018) Antifungal efficacy of Au@carbon dots nanoconjugates against opportunistic fungal pathogen, Candida albicans. Colloid Surf B Biointerfaces 163:355-361. https://doi.org/10.1016/j.colsurfb.2018.01.006

Qiao Z-A, Wang Y, Gao Y, Li H, Dai T, Liu Y, Huo Q (2010) Commercially activated carbon as the source for producing multicolor photoluminescent carbon dots by chemical oxidation. Chem Commun 46(46):8812-8814. https://doi.org/10.1039/C0CC0 $2724 \mathrm{C}$

Qin X, Lu W, Asiri AM, Al-Youbi AO, Sun X (2013) Microwaveassisted rapid green synthesis of photoluminescent carbon nanodots from flour and their applications for sensitive and selective detection of mercury (II) ions. Sens Actuators B Chem 184:156162. https://doi.org/10.1016/j.snb.2013.04.079

Ramanan V, Thiyagarajan SK, Raji K, Suresh R, Sekar R, Ramamurthy P (2016) Outright green synthesis of fluorescent carbon dots from eutrophic algal blooms for in vitro imaging. ACS Sustain Chem Eng 4(9):4724-4731. https://doi.org/10.1021/acssuschem eng.6b00935

Ramezani Z, Qorbanpour M, Rahbar N (2018) Green synthesis of carbon quantum dots using quince fruit (Cydonia oblonga) powder as carbon precursor: application in cell imaging and $\mathrm{As}^{3+}$ determination. Colloids Surf A Physicochem Eng Asp 549:58-66. https://doi.org/10.1016/j.colsurfa.2018.04.006

Ray S, Saha A, Jana NR, Sarkar R (2009) Fluorescent carbon nanoparticles: synthesis, characterization, and bioimaging application. J Phys Chem C 113(43):18546-18551. https://doi.org/10.1021/ jp905912n

Sachdev A, Gopinath P (2015) Green synthesis of multifunctional carbon dots from coriander leaves and their potential application as antioxidants, sensors and bioimaging agents. Analyst 140:4260 4269. https://doi.org/10.1039/C5AN00454C

Schneider J, Reckmeier CJ, Xiong Y, von Seckendorff M, Susha AS, Kasák P, Rogach AL (2017) Molecular fluorescence in citric acid-based carbon dots. J Phys Chem C 121(3):2014-2022. https ://doi.org/10.1021/acs.jpcc.6b12519

Sharma A, Das J (2019) Small molecules derived carbon dots: synthesis and applications in sensing, catalysis, imaging, and biomedicine. J Nanobiotech 17:92. https://doi.org/10.1186/s1295 1-019-0525-8

Shen P, Xia Y (2014) Synthesis-modification integration: one-step fabrication of boronic acid functionalized carbon dots for fluorescent blood sugar sensing. Anal Chem 86(11):5323-5329. https://doi. org/10.1021/ac5001338

Shen J, Zhu Y, Yang X, Li C (2012) Graphene quantum dots: emergent nanolights for bioimaging, sensors, catalysis and photovoltaic devices. Chem Commun 48(31):3686-3699. https://doi. org/10.1039/C2CC00110A

Shen J, Shang S, Chen X, Wang D, Cai Y (2017) Facile synthesis of fluorescence carbon dots from sweet potato for $\mathrm{Fe}^{3+}$ sensing and cell imaging. Mater Sci Eng, C 76:856-864. https://doi. org/10.1016/j.msec.2017.03.178

Shi W, Wang Q, Long Y, Cheng Z, Chen S, Zheng H, Huang Y (2011) Carbon nanodots as peroxidase mimetics and their applications to glucose detection. Chem Commun 47(23):6695-6697. https ://doi.org/10.1039/C1CC11943E

Shi B, Zhang L, Lan C, Zhao J, Su Y, Zhao S (2015a) One-pot green synthesis of oxygen-rich nitrogen-doped graphene quantum dots and their potential application in $\mathrm{pH}$-sensitive photoluminescence and detection of mercury(II) ions. Talanta 142:131-139. https://doi.org/10.1016/j.talanta.2015.04.059

Shi J, Chan C, Pang Y, Ye W, Tian F, Lyu J, Zhang Y, Yang M (2015b) A fluorescence resonance energy transfer (FRET) biosensor based on graphene quantum dots (GQDs) and gold nanoparticles (AuNPs) for the detection of mecA gene sequence of Staphylococcus aureus. Biosens Bioelectron 67:595-600. https://doi. org/10.1016/j.bios.2014.09.059

Shinde DB, Pillai VK (2012) Electrochemical preparation of luminescent graphene quantum dots from multiwalled carbon nanotubes. Chem A Eur J 18(39):12522-12528. https://doi.org/10.1002/ chem. 201201043

Sivasankaran U, Jesny S, Jose AR, Kumar KG (2017) Fluorescence determination of glutathione using tissue paper-derived carbon dots as fluorophores. Anal Sci 33(3):281-285. https://doi. org/10.2116/analsci.33.281

Sun Y-P, Zhou B, Lin Y, Wang W, Fernando KS, Pathak P, Meziani MJ, Harruff BA, Wang X, Wang H (2006) Quantum-sized carbon dots for bright and colorful photoluminescence. J Am Chem Soc 128(24):7756-7757. https://doi.org/10.1021/ja062677d

Tadessea A, RamaDevid D, Hagosa M, Battud GR, Basavaiah K (2018) Facile green synthesis of fluorescent carbon quantum dots from citrus lemon juice for live cell imaging. Asian J Nanosci Mater 1:36-46. https://doi.org/10.26655/ajnanomat.2018.1.5

Tang L, Ji R, Cao X, Lin J, Jiang H, Li X, Teng KS, Luk CM, Zeng S, Hao J (2012) Deep ultraviolet photoluminescence of watersoluble self-passivated graphene quantum dots. ACS Nano 6(6):5102-5110. https://doi.org/10.1021/nn300760g

Tao H, Yang K, Ma Z, Wan J, Zhang Y, Kang Z, Liu Z (2012) In vivo NIR fluorescence imaging, biodistribution, and toxicology of photoluminescent carbon dots produced from carbon nanotubes and graphite. Small 8(2):281-290. https://doi.org/10.1002/ smll.201101706

Thakur M, Mewada A, Pandey S, Bhori M, Singh K, Sharon M, Sharon M (2016) Milk-derived multi-fluorescent graphene quantum dotbased cancer theranostic system. Mater Sci Eng C Mater Biol Appl 67:468-477. https://doi.org/10.1016/j.msec.2016.05.007 
Tripathi KM, Tran TS, Tung TT, Losic D, Kim T (2017) Water soluble fluorescent carbon nanodots from biosource for cells imaging. J Nanomater 2017:1-10. https://doi.org/10.1155/2017/7029731

Tyagi A, Tripathi KM, Singh N, Choudhary S, Gupta RK (2016) Green synthesis of carbon quantum dots from lemon peel waste: applications in sensing and photocatalysis. RSC Adv 6:72423-72432. https://doi.org/10.1039/C6RA10488F

Vandarkuzhali SAA, Jeyalakshmi V, Sivaraman G, Singaravadivel S, Krishnamurthy KR, Viswanathan B (2017) Highly fluorescent carbon dots from Pseudo-stem of banana plant: applications as nanosensor and bio-imaging agents. Sens Actuators B Chem 252:894-900. https://doi.org/10.1016/j.snb.2017.06.088

Varma RS (2012) Greener approach to nanomaterials and their sustainable applications. Curr Opin Chem Eng 1:123-128. https://doi. org/10.1016/j.coche.2011.12.002

Varma RS (2014a) Greener and sustainable chemistry. Appl Sci 4:493497. https://doi.org/10.3390/app4040493

Varma RS (2014b) Journey on greener pathways: from the use of alternate energy inputs and benign reaction media to sustainable applications of nano-catalysts in synthesis and environmental remediation. Green Chem 16:2027-2041. https://doi. org/10.1039/C3GC42640H

Varma RS (2016) Greener and sustainable trends in synthesis of organics and nanomaterials. ACS Sustain Chem Eng 4:5866-5878. https://doi.org/10.1021/acssuschemeng.6b01623

Varma RS (2019) Biomass-derived renewable carbonaceous materials for sustainable chemical and environmental applications. ACS Sustain Chem Eng 7:6458-6470. https://doi.org/10.1021/acssu schemeng.8b06550

Vedamalai M, Periasamy AP, Wang CW, Tseng YT, Ho LC, Shih CC, Chang HT (2014) Carbon nanodots prepared from o-phenylenediamine for sensing of $\mathrm{Cu}^{2+}$ ions in cells. Nanoscale 6(21):13119-13125. https://doi.org/10.1039/C4NR03213F

Vinci JC, Ferrer IM, Seedhouse SJ, Bourdon AK, Reynard JM, Foster BA, Bright FV, Colón LA (2012) Hidden properties of carbon dots revealed after HPLC fractionation. J Phys Chem Lett 4(2):239-243. https://doi.org/10.1021/jz301911y

Wang Y, Hu A (2014) Carbon quantum dots: synthesis, properties and applications. J Mater Chem C 2:6921-6939. https://doi. org/10.1039/C4TC00988F

Wang X, Cao L, Yang ST, Lu F, Meziani MJ, Tian L, Sun KW, Bloodgood MA, Sun YP (2010) Bandgap-Like strong fluorescence in functionalized carbon nanoparticles. Angew Chem Int Ed 49(31):5310-5314. https://doi.org/10.1002/anie.201000982

Wang J, Xin X, Lin Z (2011a) Cu 2 ZnSnS 4 nanocrystals and graphene quantum dots for photovoltaics. Nanoscale 3(8):3040-3048. https ://doi.org/10.1039/C1NR10425J

Wang Q, Zheng H, Long Y, Zhang L, Gao M, Bai W (2011b) Microwave-hydrothermal synthesis of fluorescent carbon dots from graphite oxide. Carbon 49(9):3134-3140. https://doi. org/10.1016/j.carbon.2011.03.041

Wang K, Gao Z, Gao G, Wo Y, Wang Y, Shen G, Cui D (2013a) Systematic safety evaluation on photoluminescent carbon dots. Nanoscale Res Lett 8(1):122. https://doi. org/10.1186/1556-276X-8-122

Wang Q, Huang X, Long Y, Wang X, Zhang H, Zhu R, Liang L, Teng $\mathrm{P}$, Zheng H (2013b) Hollow luminescent carbon dots for drug delivery. Carbon 59:192-199. https://doi.org/10.1016/j.carbo n.2013.03.009

Wang R, Li G, Dong Y, Chi Y, Chen G (2013c) Carbon quantum dot-functionalized aerogels for $\mathrm{NO}_{2}$ gas sensing. Anal Chem 85:8065-8069. https://doi.org/10.1021/ac401880h

Wang W, Li Y, Cheng L, Cao Z, Liu W (2013d) Water-soluble and phosphorus-containing carbon dots with strong green fluorescence for cell labeling. J Mater Chem B 2(1):46-48. https://doi. org/10.1039/C3TB21370F
Wang Y, Wang S, Ge S, Wang S, Yan M, Zang D, Yu J (2013e) Facile and sensitive paper-based chemiluminescence DNA biosensor using carbon dots dotted nanoporous gold signal amplification label. Anal Methods 5(5):1328-1336. https://doi.org/10.1039/ C2AY26485D

Wang D, Chen JF, Dai L (2014a) Recent advances in graphene quantum dots for fluorescence bioimaging from cells through tissues to animals. Part Part Syst Charact 32:515-523. https://doi. org/10.1002/ppsc.201400219

Wang X, Sun X, Lao J, He H, Cheng T, Wang M, Wang S, Huang F (2014b) Multifunctional graphene quantum dots for simultaneous targeted cellular imaging and drug delivery. Colloids Surf B Biointerfaces 122:638-644. https://doi.org/10.1016/j.colsu rfb.2014.07.043

Wang J, Wei J, Sua S, Qiu J (2015a) Novel fluorescence resonance energy transfer optical sensors for vitamin B12 detection using thermally reduced carbon dots. New J Chem 39:501-507. https ://doi.org/10.1039/C4NJ00538D

Wang W, Lu Y-C, Huang H, Wang A-J, Chen J-R, Feng J-J (2015b) Facile synthesis of N, S-codoped fluorescent carbon nanodots for fluorescent resonance energy transfer recognition of methotrexate with high sensitivity and selectivity. Biosens Bioelectron 64:517-522. https://doi.org/10.1016/j.bios.2014.09.066

Wang Z, Liao H, Wu H, Wang B, Zhao H, Tan M (2015c) Fluorescent carbon dots from beer for breast cancer cell imaging and drug delivery. Anal Methods 7(20):8911-8917. https://doi. org/10.1039/C5AY01978H

Wang L, Bi Y, Gao J, Li Y, Ding H, Ding L (2016a) Carbon dots based turn-on fluorescent probes for the sensitive determination of glyphosate in environmental water samples. RSC Adv 6(89):85820-85828. https://doi.org/10.1039/C6RA10115A

Wang L, Li W, Wu B, Li Z, Wang S, Liu Y, Pan D, Wu M (2016b) Facile synthesis of fluorescent graphene quantum dots from coffee grounds for bioimaging and sensing. Chem Eng $\mathrm{J}$ 300:75-82. https://doi.org/10.1016/j.cej.2016.04.123

Wang X, Yang P, Feng Q, Meng T, Wei J, Xu C, Han J (2019) Green preparation of fluorescent carbon quantum dots from cyanobacteria for biological imaging. Polymers (Basel) 11:616. https ://doi.org/10.3390/polym11040616

Wei J, Zhang X, Sheng Y, Shen J, Huang P, Guo S, Pan J, Liu B, Feng B (2014) Simple one-step synthesis of water-soluble fluorescent carbon dots from waste paper. New J Chem 38(3):906909. https://doi.org/10.1039/C3NJ01325A

Wu ZL, Zhang P, Gao MX, Liu CF, Wang W, Leng F, Huang CZ (2013) One-pot hydrothermal synthesis of highly luminescent nitrogen-doped amphoteric carbon dots for bioimaging from Bombyx mori silk-natural proteins. J Mater Chem B 1(22):2868-2873. https://doi.org/10.1039/C3TB20418A

Xie Y, Wan B, Yang Y, Cui X, Xin Y, Guo L-H (2019) Cytotoxicity and autophagy induction by graphene quantum dots with different functional groups. J Environ Sci 77:198-209. https:// doi.org/10.1016/j.jes.2018.07.014

Xu X, Ray R, Gu Y, Ploehn HJ, Gearheart L, Raker K, Scrivens WA (2004) Electrophoretic analysis and purification of fluorescent single-walled carbon nanotube fragments. J Am Chem Soc 126(40):12736-12737. https://doi.org/10.1021/ja040082h

Xu Y, Wu M, Liu Y, Feng XZ, Yin XB, He XW, Zhang YK (2013) Nitrogen-doped carbon dots: a facile and general preparation method, photoluminescence investigation, and imaging applications. Chem Eur J 19(7):2276-2283. https://doi.org/10.1002/ chem.201203641

Xu J, Zhou Y, Liu S, Dong M, Huang C (2014) Low-cost synthesis of carbon nanodots from natural products used as a fluorescent probe for the detection of ferrum (III) ions in lake water. Anal Methods 6(7):2086-2090. https://doi.org/10.1039/C3AY4 $1715 \mathrm{H}$ 
Xu J, Lai T, Feng Z, Weng X, Huang C (2015) Formation of fluorescent carbon nanodots from kitchen wastes and their application for detection of $\mathrm{Fe}^{3+}$. Luminescence 30(4):420-424. https://doi. org/10.1002/bio.2754

Yan Z, Qu X, Niu Q, Tian C, Fan C, Ye B (2016) A green synthesis of highly fluorescent nitrogen-doped graphene quantum dots for the highly sensitive and selective detection of mercury(II) ions and biothiols. Anal Methods 8:1565-1571. https://doi.org/10.1039/ C5AY03208C

Yang S-T, Cao L, Luo PG, Lu F, Wang X, Wang H, Meziani MJ, Liu Y, Qi G, Sun Y-P (2009a) Carbon dots for optical imaging in vivo. J Am Chem Soc 131(32):11308-11309. https://doi.org/10.1021/ ja904843x

Yang S-T, Wang X, Wang H, Lu F, Luo PG, Cao L, Meziani MJ, Liu J-H, Liu Y, Chen M (2009b) Carbon dots as nontoxic and high-performance fluorescence imaging agents. J Phys Chem C 113(42):18110-18114. https://doi.org/10.1021/jp9085969

Yang X, Zhuo Y, Zhu S, Luo Y, Feng Y, Dou Y (2014) Novel and green synthesis of high-fluorescent carbon dots originated from honey for sensing and imaging. Biosens Bioelectron 60:292-298. https ://doi.org/10.1016/j.bios.2014.04.046

Yang R, Guoa X, Jia L, Zhang Y, Zhao Z, Lonshakov F (2017a) Green preparation of carbon dots with mangosteen pulp for the selective detection of $\mathrm{Fe}^{3+}$ ions and cell imaging. Appl Surf Sci 423:426432. https://doi.org/10.1016/j.apsusc.2017.05.252

Yang X, Wang Y, Shen X, Su C, Yang J, Piao M, Jia F, Gao G, Zhang L, Lin Q (2017b) One-step synthesis of photoluminescent carbon dots with excitation-independent emission for selective bioimaging and gene delivery. J Colloid Interface Sci 492:1-7. https:// doi.org/10.1016/j.jcis.2016.12.057

Yang C, Chan KK, Xu G, Yin M, Lin G, Wang X, Lin WJ, Birowosuto MD, Zeng S, Ogi T, Okuyama K, Permatasari FA, Iskandar F, Chen CK, Yong KT (2019a) Biodegradable polymer-coated multifunctional graphene quantum dots for light-triggered synergetic therapy of pancreatic cancer. ACS Appl Mater Interfaces 11:2768-2781. https://doi.org/10.1021/acsami.8b16168

Yang J, Gao G, Zhang X, Ma Y-H, Chen X, Wu F-G (2019b) One-step synthesis of carbon dots with bacterial contact-enhanced fluorescence emission: fast Gram-type identification and selective Gram-positive bacterial inactivation. Carbon 146:827-839. https ://doi.org/10.1016/j.carbon.2019.02.040

Yazid SNAM, Chin SF, Pang SC, Ng SM (2013) Detection of Sn (II) ions via quenching of the fluorescence of carbon nanodots. Microchim Acta 180(1-2):137-143. https://doi.org/10.1007/ s00604-012-0908-0

Yin B, Deng J, Peng X, Long Q, Zhao J, Lu Q, Chen Q, Li H, Tang H, Zhang Y (2013) Green synthesis of carbon dots with down-and up-conversion fluorescent properties for sensitive detection of hypochlorite with a dual-readout assay. Analyst 138(21):65516557. https://doi.org/10.1039/C3AN01003A

Yuan X, Liu Z, Guo Z, Ji Y, Jin M, Wang X (2014) Cellular distribution and cytotoxicity of graphene quantum dots with different functional groups. Nanoscale Res Lett 9:108. https://doi. org/10.1186/1556-276X-9-108

Zhang L, Xing Y, He N, Zhang Y, Lu Z, Zhang J, Zhang Z (2012) Preparation of graphene quantum dots for bioimaging application. J Nanosci Nanotechnol 12:2924-2928. https://doi.org/10.1166/ jnn.2012.5698

Zhang X, Wang S, Zhu C, Liu M, Ji Y, Feng L, Tao L, Wei Y (2013) Carbon-dots derived from nanodiamond: photoluminescence tunable nanoparticles for cell imaging. J Colloid Interface Sci 397:39-44. https://doi.org/10.1016/j.jcis.2013.01.063

Zhang H, Wang Y, Zhao D, Zeng D, Xia J, Aldalbahi A, Wang C, San L, Fan C, Zuo X, Mi S (2015a) Universal fluorescence biosensor platform based on graphene quantum dots and pyrenefunctionalized molecular beacons for detection of
microRNAs. ACS Appl Mater Interfaces 7:16152-16156. https ://doi.org/10.1021/acsami.5b04773

Zhang J, Yuan Y, Liang G, Yu SH (2015b) Scale-Up synthesis of fragrant nitrogen-doped carbon dots from bee pollens for bioimaging and catalysis. Adv Sci 2:1-6. https://doi.org/10.1002/ advs.201500002

Zhang Z, Sun W, Wu P (2015c) Highly photoluminescent carbon dots derived from egg white: facile and green synthesis, photoluminescence properties, and multiple applications. ACS Sustain Chem Eng 3(7):1412-1418. https://doi.org/10.1021/ acssuschemeng. 5 b00156

Zhang M, Zhao X, Fang Z, Niu Y, Lou J, Wu Y, Zou S, Xia S, Sun M, Du F (2017) Fabrication of HA/PEI-functionalized carbon dots for tumor targeting, intracellular imaging and gene delivery. RSC Adv 7(6):3369-3375. https://doi.org/10.1039/ C6RA26048A

Zhao HX, Liu LQ, De Liu Z, Wang Y, Zhao XJ, Huang CZ (2011) Highly selective detection of phosphate in very complicated matrixes with an off-on fluorescent probe of europium-adjusted carbon dots. Chem Commun 47(9):2604-2606. https://doi. org/10.1039/C0CC04399K

Zhao J, Yan Y, Zhu L, Li X, Li G (2013) An amperometric biosensor for the detection of hydrogen peroxide released from human breast cancer cells. Biosens Bioelectron 41:815-819. https://doi. org/10.1016/j.bios.2012.10.019

Zhao S, Lan M, Zhu X, Xue H, Ng T-W, Meng X, Lee C-S, Wang P, Zhang W (2015) Green synthesis of bifunctional fluorescent carbon dots from garlic for cellular imaging and free radical scavenging. ACS Appl Mater Interfaces 7(31):17054-17060. https:// doi.org/10.1021/acsami.5b03228

Zheng XT, Than A, Ananthanaraya A, Kim D-H, Chen P (2013) Graphene quantum dots as universal fluorophores and their use in revealing regulated trafficking of insulin receptors in adipocytes. ACS Nano 7(7):6278-6286. https://doi.org/10.1021/nn4023137

Zheng XT, Ananthanarayanan A, Luo KQ, Chen P (2015) Glowing graphene quantum dots and carbon dots: properties, syntheses, and biological applications. Small 11(14):1620-1636. https://doi. org/10.1002/smll.201402648

Zhou J, Booker C, Li R, Zhou X, Sham T-K, Sun X, Ding Z (2007) An electrochemical avenue to blue luminescent nanocrystals from multiwalled carbon nanotubes (MWCNTs). J Am Chem Soc 129(4):744-745. https://doi.org/10.1021/ja0669070

Zhou J, Han T, Ma H, Yan T, Pang X, Li Y, Wei Q (2015) A novel electrochemiluminescent immunosensor based on the quenching effect of aminated graphene on nitrogen-doped carbon quantum dots. Anal Chim Acta 889:82-89. https://doi.org/10.1016/j. aca.2015.07.018

Zhou Y, Sun H, Wang F, Ren J, Qu X (2017) How functional groups influence the ROS generation and cytotoxicity of graphene quantum dots. Chem Commun 53:10588-10591. https://doi. org/10.1039/C7CC04831A

Zhu S, Zhang J, Qiao C, Tang S, Li Y, Yuan W, Li B, Tian L, Liu F, Hu R, Gao H, Wei H, Zhang H, Sun H, Yang B (2011) Strongly green-photoluminescent graphene quantum dots for bioimaging applications. Chem Commun (Camb) 47:6858-6860. https://doi. org/10.1039/C1CC11122A

Zhu A, Luo Z, Ding C, Li B, Zhou S, Wang R, Tian Y (2014) A twophoton "turn-on" fluorescent probe based on carbon nanodots for imaging and selective biosensing of hydrogen sulfide in live cells and tissues. Analyst 139(8):1945-1952. https://doi.org/10.1039/ C3AN02086J

Zhu S, Song Y, Zhao X, Shao J, Zhang J, Yang B (2015) The photoluminescence mechanism in carbon dots (graphene quantum dots, carbon nanodots, and polymer dots): current state and future perspective. Nano Res 8(2):355-381. https://doi.org/10.1007/s1227 4-014-0644-3 
Zong J, Zhu Y, Yang X, Shen J, Li C (2011) Synthesis of photoluminescent carbogenic dots using mesoporous silica spheres as nanoreactors. Chem Commun 47(2):764-766. https://doi.org/10.1039/ C0CC03092A

Zou Y, Yan F, Zheng T, Shi D, Sun F, Yang N, Chen L (2015) Highly luminescent organosilane-functionalized carbon dots as a nanosensor for sensitive and selective detection of quercetin in aqueous solution. Talanta 135:145-148. https://doi.org/10.1016/j. talanta.2014.12.029
Publisher's Note Springer Nature remains neutral with regard to jurisdictional claims in published maps and institutional affiliations. 